"Carbohydrate DNA interaction at G-quadruplexes: folding and stability changes by attaching sugars at the 5'-end”. Gómez-Pinto, I., Vengut-Climent, E., Lucas, R., Aviñó, A., Eritja, R., González, C., Morales, J.C. Chem. Eur. J., 19, 1920-1927 (2013).

Doi: $10.1002 /$ chem.201203902

\title{
Carbohydrate-DNA Interactions at G-Quadruplexes: Folding and Stability Changes by Attaching Sugars at the 5'-End
}

\author{
Irene Gómez-Pinto, ${ }^{[\mathrm{a}]}$ Empar Vengut-Climent, ${ }^{[\mathrm{b}]}$ Ricardo Lucas, $^{[\mathrm{b}]}$ \\ Anna Avinó, ${ }^{[\mathrm{c}]}$ Ramón Eritja, ${ }^{[\mathrm{c}]}$ Carlos González, ${ }^{*}{ }^{[\mathrm{a}]}$ and Juan Carlos \\ Morales ${ }^{*}[\mathrm{~b}]$
}
[a] Instituto de Química Física "Rocasolano", CSIC, Serrano 119, 28006 Madrid (Spain) E-mail: cgonzalez@iqfr.csic.es
${ }^{[b]}$ Department of Bioorganic Chemistry Instituto de Investigaciones Químicas CSIC- Universidad de Sevilla Americo Vespucio 49, 41092 Sevilla (Spain) E-mail: jcmorales@iiq.csic.es
${ }^{[c]}$ Instituto de Investigación Biomédica de Barcelona, IQAC, CSIC, CIBER-BBN Networking Centre on Bioengineering Biomaterials and Nanomedicine Baldiri Reixac 10, 08028 Barcelona (Spain)

\begin{abstract}
Quadruplex DNA structures are attracting an enormous interest in many areas of chemistry, ranging from chemical biology, supramolecular chemistry to nanoscience. We have prepared carbohydrate-DNA conjugates containing the oligonucleotide sequences of Gquadruplexes (thrombin binding aptamer (TBA) and human telomere (TEL)), measured their thermal stability and studied their structure in solution by using NMR and molecular dynamics. The solution structure of a fucose-TBA conjugate shows stacking interactions between the carbohydrate and the DNA G-tetrad in addition to hydrogen bonding and hydrophobic contacts. We have also shown that attaching carbohydrates at the $5^{\prime}$-end of a quadruplex telomeric sequence can alter its folding topology. These results suggest the possibility of modulating the folding of the G-quadruplex by linking carbohydrates and have clear implications in molecular recognition and the design of new G-quadruplex ligands.
\end{abstract}

Keywords: carbohydrates; DNA; G-quadruplexes; hydrogen bonds; molecular interactions; stacking

\section{Introduction}

G-quadruplexes consist of a square arrangement of guanines (G-tetrad), stabilized by Hoogsteen hydrogen-bonding and by monovalent cations (especially potassium) coordinated in the center, located between two G-tetrads. The in vivo evidence of the existence of G-quadruplexes at telomeres[1] and oncogene promoters,[2] as well as their role in controlling different biological processes,[3] have converted them in primary research targets for therapeutical applications. [4] Consequently, a variety of ligands has been designed and prepared to bind Gquadruplexes as a new class of anticancer drugs. Some examples of quadruplex binders have been reported to bind through groove specific contacts of the quadruplex structure.[5] However, most quadruplex ligands described to date use aromatic $\pi$-stacking as the main driving force for binding on the G-tetrad platform.[6]

In addition, G-quadruplexes are a very attractive motif in the development of structural and functional supramolecular assemblies,[7] and in DNA-based nanodevices.[8] The possibility of modulating the physicochemical properties of a G-quadruplex by its conjugation to small molecules is also being explored, especially through attaching large aromatic groups.[9] 
We have used carbohydrate oligonucleotide conjugates (COCs) to study carbohydrate-DNA interactions in double helices adapting a dangling end DNA model system traditionally used to study $\pi-\pi$ stacking interactions.[10] The sugar moiety is attached to the $5^{\prime}$-end of the DNA sequence in our COCs. In previous work, we observed that natural highly polar carbohydrates stack onto the terminal DNA base pair of a duplex through $\mathrm{CH} / \pi$ interactions. [11] However, DNA stability is only increased when the sugars stack on $\mathrm{C}-\mathrm{G}$ or $\mathrm{G}-\mathrm{C}$ base pairs. If COCs contained permethylated carbohydrates, apolar versions of the natural sugars, a notable increase in double-stranded DNA stability was found in comparison with the natural polyhydroxylated mono- and disaccharide DNA conjugates. Moreover, these apolar carbohydrates are also capable of stabilizing duplexes with A-T or T-A terminal base-pairs.[12] We hypothesized that the $\mathrm{CH}-\pi$ pseudo hydrogen-bonds in addition to the higher hydrophobicity imparted by the methyl groups are responsible for duplex stabilization.

Due to the relevance of the G-quadruplex DNA and RNA structures we decided to explore the possible carbohydrate- DNA interactions in a G-quadruplex context. Herein we describe the preparation of COCs containing the oligonucleotide sequence of a G-quadruplex and sugars attached to the $5^{\prime}$-end. The idea was to examine the possibility of carbohydrate interactions on top of the nearby G-tetrad and investigate how these contacts could affect quadruplex stability and structure. We have prepared COCs containing the thrombin-binding aptamer (TBA) and the human telomere (TEL) sequences in which the carbohydrates were covalently linked through an ethylene glycol spacer (Figure 1). Saccharides conjugated to a Gquadruplex-forming sequence (5'-TGGGAG) have been reported previously as antiHIV agents.[13] The TBA sequence (Figure 1A) was selected due to the detailed knowledge of its 3D structure[14] and because of the high number of chemically modified TBA sequences (containing reverse natural bases,[15] extra natural bases,[16] modified bases,[17] and unnatural nucleosides[18]) and TBA conjugates (linked to small molecules[19] and to nanostructures).[20]

A TBA seq (1) = 5'- $-G^{1} G^{2} T^{3} T^{4} G^{5} G^{6} T^{7} G^{8} T^{9} G^{10} G^{11} T^{12} T^{13} G^{14} G^{15}$
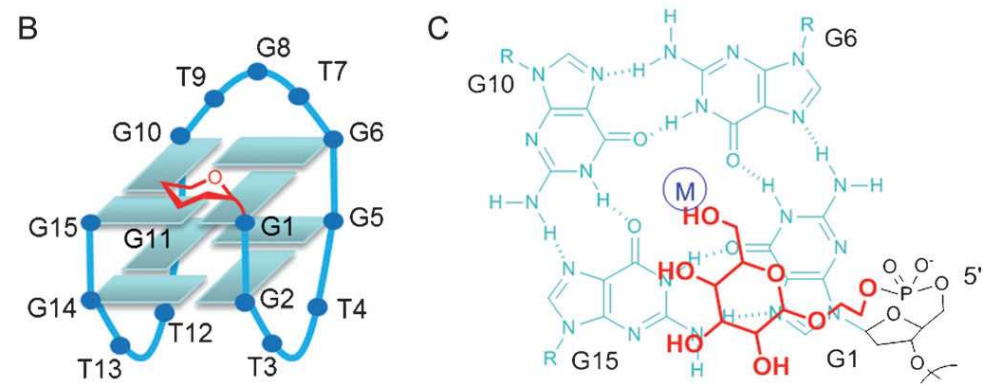

Figure 1. A) Sequence of the thrombin-binding aptamer (TBA). B) Schematic model of the carbohydrate-TBA conjugates. C) Enlarged top-view of monosaccharide-TBA conjugate.

\section{Results and Discussion}

The COCs were synthesized by using standard solid-phase oligonucleotide automatic synthesis. Mono- and disaccharides were covalently bound to the TBA sequence by using the corresponding carbohydrate phosphoramidite derivative (Figure 1 and Figure 2).[11, 21] $\beta$-D-glucose, $\beta$-D-galactose and $\beta$-D-fucose were selected monsaccarides, whereas $\beta$-D-maltose, $\beta$-D-lactse ans $\beta$-D-cellobiose were the chosen 
disaccharides. Also, two apolar sugars, permethylated glucose and maltose, were attached to the TBA sequence by using a similar synthetic strategy [12].

The thermal stability of the carbohydrate TBA conjugates was measured by UV-monitored thermal denaturation experiments in a $\mathrm{pH} 7.0$ cacodylate buffer containing $\mathrm{KCl}(100 \mathrm{mM})$ (Table 1). All COCs containing natural carbohydrates (4-9) showed a lower thermal stability than the natural TBA (1). The reduction in $T_{m}$ values ranges from 5.7 to $6.8{ }^{\circ} \mathrm{C}$. However, it is important to note that the addition of a phosphate group at the $5^{\prime}$-end of the TBA quadruplex (compound $\mathbf{2}$ ) provokes a destabilization of $4.5{ }^{\circ} \mathrm{C}$ with respect to unmodified TBA $\mathbf{1}$. Furthermore, when the spacer is attached to the TBA sequence (compound $\mathbf{3}$ ) the decrease of $T_{m}$ in comparison with TBA is $7.5^{\circ} \mathrm{C}$. Therefore, compound $\mathbf{3}$ must be considered the proper control to evaluate the carbohydrate contribution to the thermal stability of the different conjugates. Thus, $\Delta T_{m}$ values of the natural carbohydrate TBA conjugates (4-9) with respect to the spacer- TBA conjugate (3) indicate an increase in stability between 0.7 and $1.8^{\circ} \mathrm{C}$ (see right column on Table 1). Thermodynamic analysis of the UV melting-curves were obtained by curve-fitting as described in the literature.[22] Free energies confirmed the trend observed in the $T_{m}$ values. Moreover, $a$ greater enthalpic contribution to the stability of their folded structure is observed in all carbohydrate-TBA conjugates with respect to the spacerTBA conjugate (3) and to natural TBA (1), which could be attributed to the new molecular interactions between carbohydrates and the G-quadruplex.

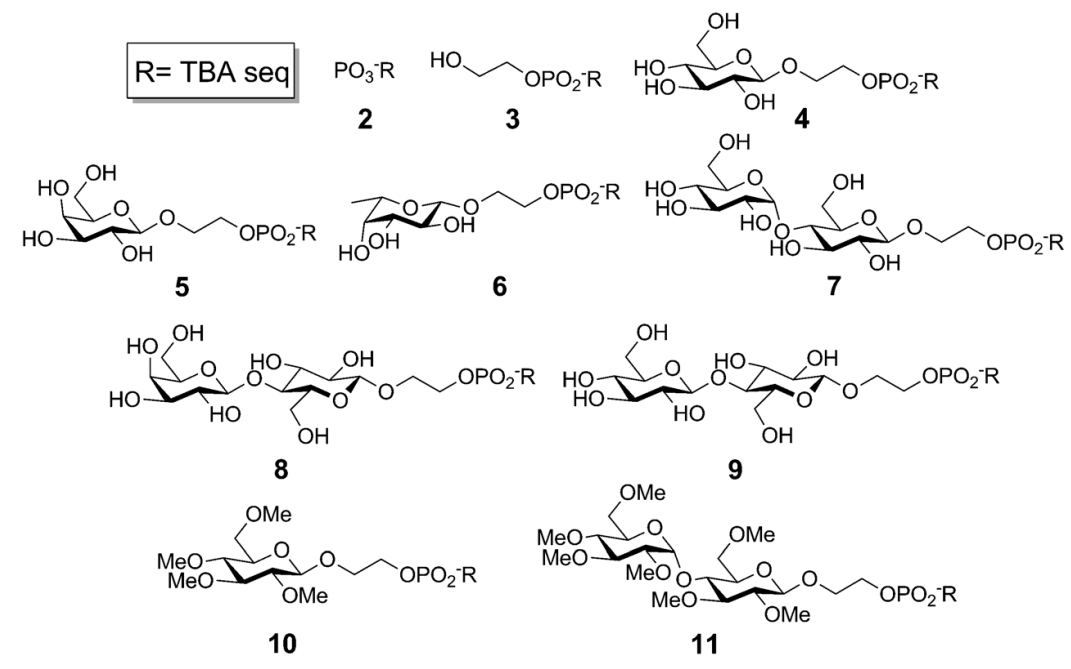

Figure 2. Carbohydrate-TBA conjugates and oligonucleotide controls prepared for this study.

A similar scenario is observed when apolar carbohydrates are bound to the $5^{\prime}$-end of the TBA oligonucleotide. COCs containing permethylated glucose and maltose (10 and 11) also show a decrease in $T_{m}$ values in comparison with TBA (4.7 and $10.1{ }^{\circ} \mathrm{C}$, respectively). Nevertheless, the TBA conjugate with the apolar version of glucose (10) is $2.8^{\circ} \mathrm{C}$ more stable than the control spacer- TBA (3) contributing to moderately improved TBA stability. The addition of the natural and sugars to the conjugate $\mathbf{3}$ is able to 
recover, to some extent, the TBA G-quadruplex stability. These results indicate that favorable carbohydrate- DNA interactions are taking place.

We also measured the thermal stability of oligonucleotide TBA sequences with an extra base at the 5'-end (thymidine, sequence 12 and adenine, sequence 13). A decrease in $T_{m}$ value was observed for both sequences (6.0 and $6.3^{\circ} \mathrm{C}$, respectively) with respect to the unmodified TBA (1). Comparable results were obtained by Smirnov et al.;[23] these values are similar to those obtained for COCs with the natural carbohydrates and a similar behavior could be envisioned. It is important to note that here the "spacer" of the natural aromatic base is deoxyribose, which is conformationally more restricted than ethylene glycol, the spacer used for the mono- and disaccharide TBA conjugates.

To confirm that the observed increased stability in COCs is due to carbohydrate-G-tetrad interaction, the structure of TBA-carbohydrate conjugates containing two mono- and three disaccharides (compounds 5, 6, $\mathbf{7}, \mathbf{8}$, and 9) was studied by NMR spectroscopy, circular dichroism (CD), and gel electrophoresis. CD spectra clearly show that all conjugates adopt antiparallel G-quadruplex structures (see Figure S1 in the Supporting Information). Gel electrophoresis experiments conducted under nondenaturating conditions show single bands for monosaccharide-TBA conjugates, running as the native TBA. However, two bands are observed for the disaccharide-TBA conjugates (Figure S2 in the Supporting Information). Since the melting temperatures of these conjugates do not depend on oligonucleotide concentration (Table S1 in the Supporting Information), we conclude that the two bands observed in the gels correspond to two monomeric species with different conformations.

Table 1. Melting temperatures $T_{m}$ values $\left({ }^{\circ} \mathrm{C}\right)$ for the carbohydrate-oligonucleotide conjugates containing the thrombin-binding aptamer sequence and the corresponding oligonucleotide controls.[a]

\begin{tabular}{|c|c|c|c|c|c|c|c|c|}
\hline$\frac{5^{\prime}-\mathbf{X}-}{\text { GGTTGGTGTGTTGG }}$ & $\begin{array}{l}T_{m} \\
(0 \\
\text { C) }\end{array}$ & $\begin{array}{c}\Delta T_{m} \\
{\left[{ }^{\circ} \mathrm{C}\right]^{[b]}}\end{array}$ & $\begin{array}{c}\Delta T_{m}{ }^{*} \\
{\left[{ }^{\circ} \mathrm{C}\right]^{[\mathrm{c}]}}\end{array}$ & $\begin{array}{c}-\Delta S^{\circ} \\
(\mathrm{cal} / \mathrm{k} \\
\mathrm{mol} \text {. }\end{array}$ & $\begin{array}{c}-\Delta H^{\circ} \\
(\mathrm{kcal} / \mathrm{mol})\end{array}$ & $\begin{array}{c}\Delta G^{\circ}{ }_{37} \\
(\mathrm{kcal} / \mathrm{mol})\end{array}$ & $\begin{array}{c}\Delta \Delta G_{37}^{\circ} \\
(\mathrm{kcal} / \mathrm{mol})^{[\mathrm{d}]}\end{array}$ & $\begin{array}{c}\Delta \Delta G^{\circ}{ }_{37}^{*} \\
(\mathrm{kcal} / \mathrm{mol})^{[\mathrm{e}]}\end{array}$ \\
\hline (none) 1 & $\begin{array}{l}48.2 \\
\pm 0.5\end{array}$ & - & -7.5 & $117.5 \pm 2$ & 37.7 & -2.8 & - & -1.0 \\
\hline $\mathrm{PO}_{3}^{-[f]}$ & $\begin{array}{l}43.7 \\
\pm 0.2\end{array}$ & -4.5 & -3.0 & $134.1 \pm 2$ & 42.3 & -2.3 & 0.5 & -0.5 \\
\hline $\mathrm{HO}-\mathrm{C} 2-\mathrm{OPO}_{2}^{-[\mathrm{f}]}$ & $\begin{array}{l}40.7 \\
\pm 0.2\end{array}$ & -7.5 & - & $119.8 \pm 1$ & 37.5 & -1.8 & 1.0 & - \\
\hline$\beta$-D-glucose-C2-OPO ${ }_{2}^{-[f]}$ & $\begin{array}{l}42.5 \\
\pm 0.2\end{array}$ & -5.7 & +1.8 & $132.3 \pm 1$ & 41.7 & -2.2 & 0.6 & -0.4 \\
\hline$\beta$-D-galactose-C2-OPO ${ }_{2}^{-}$ & $\begin{array}{l}41.4 \\
\pm 0.2\end{array}$ & -6.8 & +0.7 & $135.1 \pm 2$ & 42.3 & -2.0 & 0.8 & -0.2 \\
\hline$\beta$-L-fucose-C2-OPO ${ }_{2}^{-[f]} 6$ & $\begin{array}{l}42.3 \\
\pm 0.2\end{array}$ & -5.9 & +1.6 & $135.7 \pm 2$ & 42.6 & -2.2 & 0.6 & -0.4 \\
\hline$\beta$-D-maltose-C2-OPO ${ }_{2}^{-[\mathrm{f}]}$ & $\begin{array}{l}41.7 \\
\pm 0.2\end{array}$ & -6.5 & +1.0 & $133.7 \pm 2$ & 42.0 & -2.1 & 0.7 & -0.3 \\
\hline$\beta$-D-lactose-C2-OPO ${ }_{2}^{-[\mathrm{f}]} \mathbf{8}$ & $\begin{array}{l}41.5 \\
\pm 0.3\end{array}$ & -6.7 & +0.8 & $139.7 \pm 2$ & 43.8 & -2.2 & 0.6 & -0.4 \\
\hline$\beta$-D-cellobiose-C2-OPO & $\begin{array}{l}41.8 \\
\pm 0.3\end{array}$ & -6.4 & +1.1 & $136.9 \pm 2$ & 42.9 & -2.1 & 0.7 & -0.3 \\
\hline $\begin{array}{r}\beta \text {-D-glucose }(\mathrm{Me})-\mathrm{C} 2-\mathrm{OPO}_{2}^{-} \\
{ }_{[\text {[f] }} \mathbf{1 0}\end{array}$ & $\begin{array}{l}43.5 \\
\pm 0.7\end{array}$ & -4.7 & +2.8 & $134.1 \pm 1$ & 42.4 & -2.4 & 0.4 & -0.6 \\
\hline$\beta$-D-maltose(Me)-C2- & $\begin{array}{l}38.1 \\
\pm 0.4\end{array}$ & -10.1 & -1.6 & $\begin{array}{c}127.2 \\
\pm 2\end{array}$ & 39.7 & -1.8 & 1.0 & 0.0 \\
\hline
\end{tabular}




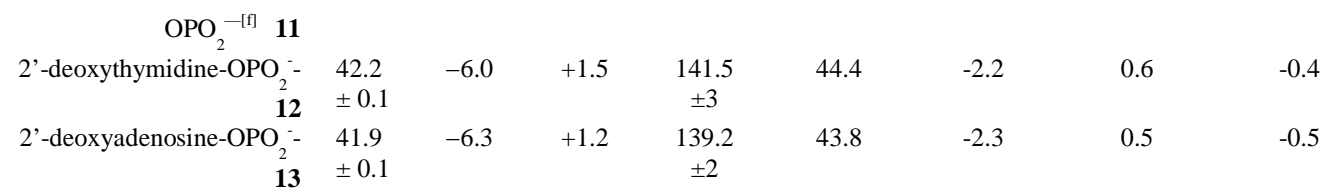

[a] Buffer: $10 \mathrm{mM}$ Nacacodylate, $100 \mathrm{mM} \mathrm{KCl}, \mathrm{pH} 7.0 ; T_{m}$ values are the average of three experiments measured at $5 \mu \mathrm{M}$ conc.; [b] $\Delta T_{m}=T_{m}\left(5^{\prime}\right.$ modified TBA sequence) $-T_{m}$ (TBA control sequence); [c] $\Delta T_{m}^{*}=T_{m}$ (5'-modified TBA sequence) $-T_{m}$ (5'-spacer-OPO $2^{--}$TBA sequence). [d] $\Delta \Delta G^{\circ}{ }_{37}=\Delta G$ (5'-modified TBA sequence) $-\Delta G$ (TBA control sequence); [e] $\Delta \Delta G^{\circ}{ }_{37} *=\Delta G$ (5'-modified TBA sequence) $-\Delta \mathrm{G}$ (5'-spacer$\mathrm{OPO} 2^{-}-\mathrm{TBA}$ sequence). [f] $\mathrm{C} 2$ stands for $-\mathrm{CH}_{2}-\mathrm{CH}_{2}-$;

The imino proton region of the NMR spectra clearly indicates that all conjugates adopt a quadruplex structure with two guanine tetrads (Figure S3 in the Supporting Information). Exchangeable proton signals could be assigned on the basis of the strong similarity between the spectra of the conjugates and the unmodified aptamer. Assignment of most nonexchangeable protons could be carried out following standard bidimensional techniques, and were confirmed with previously reported assignment of native TBA (see Figures 3 and 4 and the Supporting Information for assignment tables).

In the case of the disaccharide conjugates, spectral assignment was complicated due to the presence of additional spin-systems. After sequential assignment, we concluded that these systems correspond to two species, affecting protons in residues G6, T7, and G8 (see Figure 3), being both species in slow equilibrium on the NMR timescale. The chemical shifts of one of the conformations are almost coincident with those of the native aptamer.

This effect is not observed in the monosaccharide-TBA conjugates, in which single species are observed. The different behavior between monoand disaccharide conjugates is consistent with the non-denaturating gel experiments. Chemical shift differences between equivalent protons in modified- and unmodified TBA are shown in Figure S4 (the Supporting Information). Most protons in COCs exhibit very similar chemical shifts to the natural TBA except those in residue $\mathrm{G} 1$ and in the neighborhood of the TGT loop (mainly, protons in residues G6, T7, and G8). Interestingly, the profile of chemical shift differences is very similar in all the conjugates.

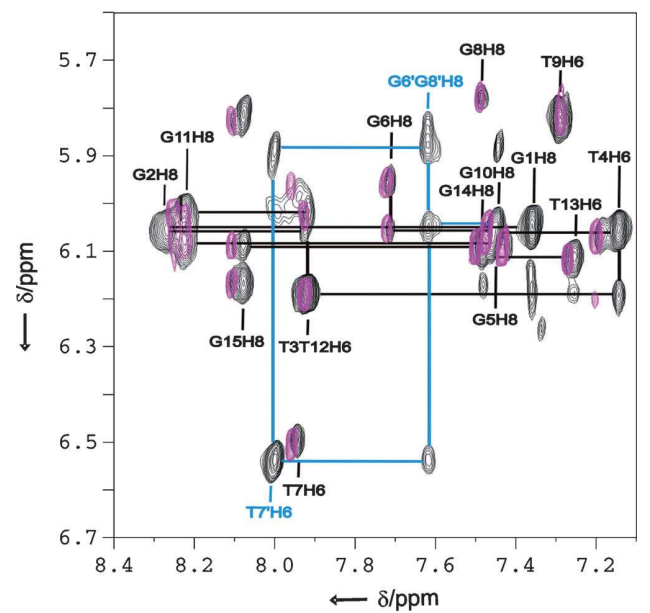


Figure 3. Region of the NOESY spectra of the maltose-TBA conjugate (7) superimposed onto the native TBA (1, pink) spectra. Sequential assignment pathways show the two different species for residues G6, T7 and G8 (labeled in different colors).

NOE data also indicate that all conjugates maintain a similar structure as the native TBA. Exchangeable NOE patterns are consistent with formation of two G-tetrads. The strong intensities of intraresidue NOE crosspeaks between guanine $\mathrm{H} 8$ and $\mathrm{H}^{\prime}{ }^{\prime}$ protons confirmed the syn conformation for the glycosydic angle of $\mathrm{G} 1, \mathrm{G} 5, \mathrm{G} 10$, and G14. Stacking of the lateral loop thymines, T4 and T13, on top of the adjacent guanines, G2 and G11, is corroborated by several strong NOEs. However, some differences in NOE cross-peaks are observed in the TGT loop suggesting that the carbohydrate affects its structure and alters the interaction of residues G8 and T9 with the nearby tetrad (G1:G6:G10:G15; see Figure 4 and Table $S 2$ in the Supporting Information).
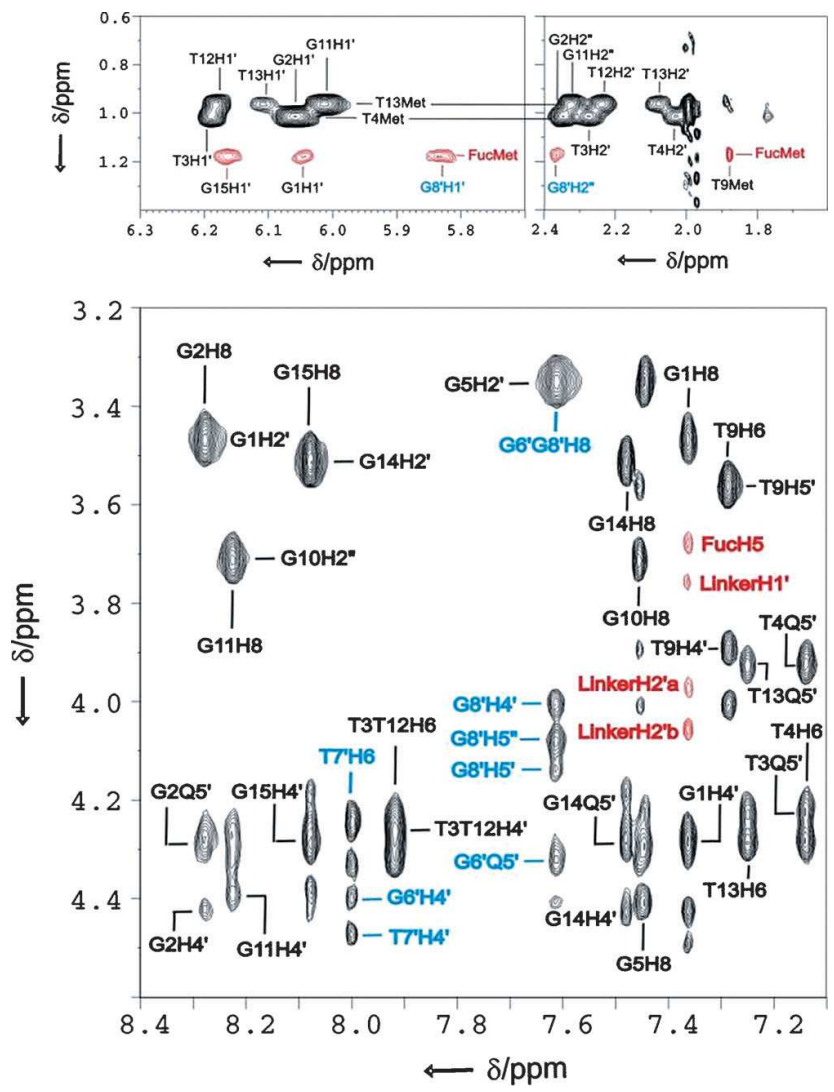

Figure 4. Regions of the NOESY experiments of fucose-TBA conjugate (6). Contour plots of the carbohydrate-DNA NOEs are shown in red.

Most interestingly, several carbohydrate-DNA NOEs could be detected in all conjugates. The number of these NOEs is particularly high in the case of conjugate 6 (fucose-TBA), most probably due to the presence of a methyl group in this carbohydrate; this resonance is easily identified and does not overlap with other signals of the conjugate (see Figure 4, top). 
The solution structure of conjugate $\mathbf{6}$ was determined on the basis of experimental NOE constraints. Restrained molecular- dynamics calculations were carried out with the AMBER package as explained in the Methods section in the Supporting Information. A total of 142 distance constraints (10 between carbohydrate and DNA) were used in the calculation (Table S2, the Supporting Information). Structures were deposited in the Protein Data Bank (2lyg). As shown in Figure 5, the resulting structures are well-defined. The solution structure of the fucose-TBA conjugate resembles the general fold of the unmodified aptamer. The main differences are in the TGT loopregion in which the fucose moiety displaces the nucleobases of residues G8 and T9 and stacks on top of G1 and G15 (see Figure 5, bottom). In fact, fucose interaction with the guanine tetrad seems to occur by an induced-fit mechanism. In addition to the stacking interaction with the adjacent tetrad, fucose $\mathrm{O5}$ is at a hydrogen bond distance of one amino proton of $\mathrm{G} 8$ (see Figure 6). Also, a favorable hydrophobic interaction occurs between fucose and T9 methyl groups (Figure 6). The T7 base tends to insert into the quadruplex groove. The carbohydrate maintains the usual 4C1 chair conformation.

The structure of the conjugate $\mathbf{6}$ is totally consistent with the observed NOEs and the profiles of chemical shift differences between this conjugate and the native aptamer. Chemical shifts are very sensitive to structural variations. Therefore, the strong similarity between DNA proton resonances in the two monosaccharide-DNA conjugates implies that fucose-TBA and galactose-TBA adopt very similar conformations (see Figure S5 in the Supporting Information). Although in the latter the number of carbohydrate- DNA NOEs is lower, this is not due to a different conformation of the galactose in the conjugate, but to the lack of the fucose methyl-group that facilitates the detection of carbohydrate- DNA NOEs.

Inspection of the structure of fucose-TBA shows that the site occupied by the fucose sugar cannot be easily occupied by a disaccharide without further disruption of the TGT loop (see Figure 5). Most probably, this is the reason of the two species observed in the NMR spectra of the disaccharide conjugates, and confirmed by electrophoretic gels. ${ }^{1} \mathrm{H}$ chemical shifts and NOEs suggest that in one species the disaccharide interacts with the G-tetrad disrupting the TGT loop, and in the other, the TGT loop adopts a native-like conformation with the disaccharide mainly disordered (Figure 7). Presumably, this second species has a different electrophoretic mobility (see Figure $\mathrm{S} 2$ in the Supporting Information). At the same time, this equilibrium must be affecting the stability of the carbohydrate-TBA conjugate.

It is worth mentioning that the disaccharide-TBA conjugates are not more stable than the monosaccharide-TBA conjugates, as observed in the case of sugar-capping DNA duplexes.[11-12] The stabilization conferred to the TBA by the different carbohydrates is more difficult to interpret than in the case of carbohydrates stacking at the terminal base of double helices. In the latter, the increase in thermal stability is a direct measurement of a favorable interaction of the carbohydrate with the terminal base pair. However, in TBA conjugates the carbohydrate G-tetrad interaction competes with native nucleobase $\pi$-stacking interactions. This event is difficult to 
circumvent because G-tetrads are rarely exposed to the solvent. In fact, the capping interactions in the terminal G-tetrads affect dramatically the folding topology of the quadruplex.

Interfering with capping interactions by conjugating carbohydrates makes it possible to modulate G-quadruplex folding, since the particular topology adopted by a G-rich oligonucleotide depends strongly on capping interactions between terminal G-tetrads and nucleotides in the loops. In many cases, terminal residues are also involved in these interactions, as observed in human telomeric sequences. As a proof of concept, we have explored the effect of substituting the 5'- terminal thymine of the oligonucleotide 5'-TAGGGTTAGGGT- 3' (TEL) with a carbohydrate. TEL folds as a G-quadruplex containing two repeats of the human telomeric sequence, and its structure has been studied by NMR spectroscopy and Xray crystallography. In the crystallographic structure TEL forms a dimeric parallel propeller-like quadruplex.[24] However, in solution, TEL exists in an equilibrium between dimeric parallel and antiparallel structures, being the latter predominant in $\mathrm{Na}^{+}$buffer.[25]

As it can be observed in Figure 8 , the NMR spectra of TEL and $\beta$-Dglucose-C2-OPO 2 -AGGGTTAGGGT 14 are dramatically different. As previously reported, the TEL spectra exhibit many broad imino signals, indicating the presence of multiple conformations. A similar complexity is observed in the control spacer-OPO 2 -AGGGTTAGGGT conjugate 15 (see Figure S9 in the Supporting Information).
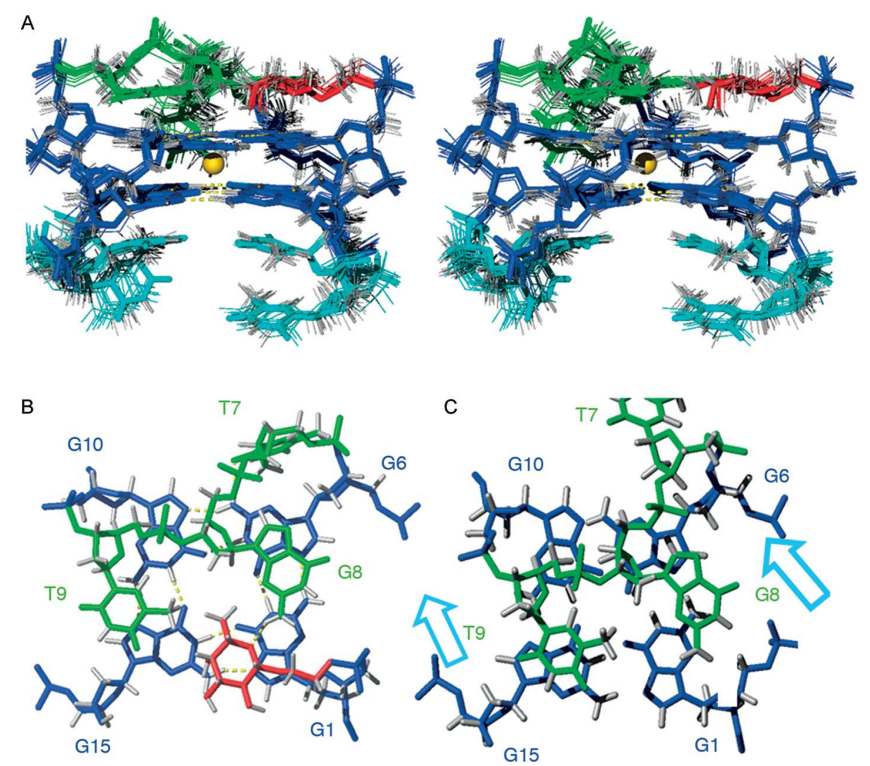

Figure 5. A) Stereoview of the superposition of 10 refined structures of the fucose-TBA, conjugate 6 . The average structure is shown in bold bonds. B) Top view of the fucose-TBA conjugate 6. C) Top view of the native TBA G-quadruplex 1 (arrows indicate the direction where G8 and T9 move in the fucose-TBA conjugate 6). The fucose moiety is shown in red, guanine core in blue, _TT_ lateral loops in cyan, and the _TGT_loop in green. 


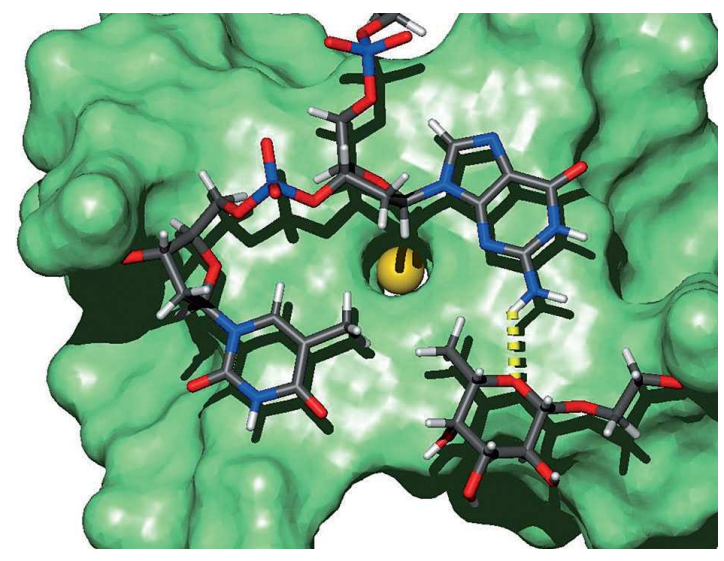

Figure 6. Detail on the structure of the fucose-TBA conjugate $\mathbf{6}$. Contacts of fucose with the bases of G8 and T9 in the TGT loop of the G-quadruplex can be observed (methyl-methyl interactions and a hydrogen bond shown in yellow).

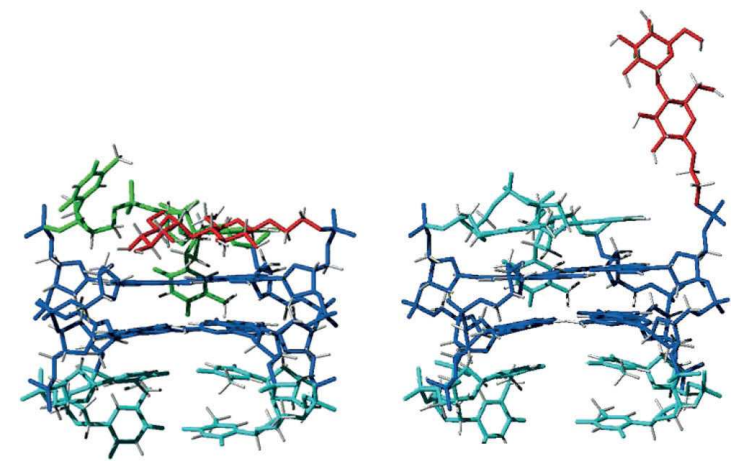

Figure 7. Side view of the two possible conformations of maltose-TBA conjugate 7: Left: maltose stacked on the G-tetrad with T9 shifted; right: maltose pointing to the bulk aqueous solution with T9 and G8 stacked on the G-tetrad.
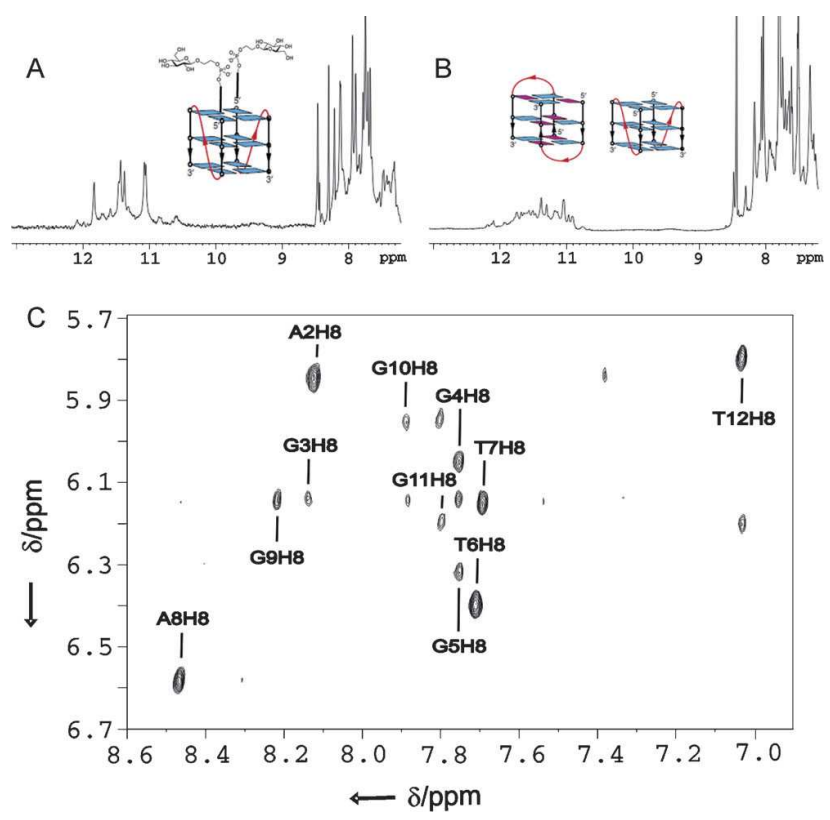
Figure 8. Imino region of the NMR spectra of A) $\mathbf{1 4}$ and B) TEL and schemes of the two species coexistent in solution; C) $\mathrm{H}_{1}$ '-aromatic region of the NOESY spectra of 14 in $\mathrm{D}_{2} \mathrm{O}$ $\left(\tau_{\mathrm{m}}=300 \mathrm{~ms}\right.$ ) (Experimental conditions: oligo concentration $=1 \mu \mathrm{m}$, potassium phosphate buffer $\left.(10 \mathrm{mM}), \mathrm{pH} \mathrm{7,} \mathrm{T}=5^{\circ} \mathrm{C}\right)$.

However, the imino region of the NMR spectra of the carbohydrateTEL conjugate 14 shows six sharp signals, indicating clearly the presence of a single conformation. The two-dimensional spectrum of $\mathbf{1 4}$ shown in Figure 8 indicates that all guanines are in an anti-conformation. These data are consistent with the formation of a parallel symmetric quadruplex. A complete structural determination of this and other COCs containing telomeric sequences is in progress in our laboratories and will be reported in due time. With the present data we can already conclude that substitution of the 5'-terminal thymine by glucose alters the equilibrium between different species, promoting the formation of a stable parallel quadruplex (see Figure 8).

\section{Conclusion}

Our studies on sugar-DNA conjugates show that favorable carbohydrate-DNA interactions occur in a G-quadruplex structural context as we have observed in the case of TBA. Carbohydrates stack on top of guanine tetrads, and also interact with loop DNA bases through hydrogen bonding or hydrophobic contacts when they are available (like the interaction between fucose and thymine methyl groups in the fucose-TBA conjugate).

Our results have implications in the design of new G-quadruplex ligands. Until now only aromatic compounds binding through $\pi-\pi$ stacking on the guanine tetrad or through van der Waals contacts with the grooves of the G-quadruplex structures have been reported. Our results engage the possibility of developing carbohydrate-based ligands that could bind through $\mathrm{CH}-\pi$ noncovalent forces together with other molecular interactions.

Finally, we have also shown that by conjugating carbohydrates at the 5 '-end of G-quadruplex structures, we can alter their folding topology. The success of the modulation is based on manipulating the interaction between the terminal G-tetrads and other residues. The intrinsic versatility of carbohydrates introduces the possibility of modulating G-quadruplex systems in nanomaterials and biomedical applications.

\section{Acknowledgements}

We thank the MICINN (grants CTQ2009-13705, CTQ2010-20451, CTQ2010-21567-C02-02), EU COST project MP0802, Generalitat de Catalunya (2009/SGR/208), and Instituto de Salud Carlos III (CIBERBNN, CB06 01 0019) for financial support. IGP and RL thank CSIC for a JAE contract. EVC thanks the Ministry of Education for an FPU doctoral fellowship.

\section{REFERENCES}

[1] K. Paeschke, T. Simonsson, J. Postberg, D. Rhodes, H. J. Lipps, Nat Struct Mol Biol 2005, 12, $847-854$. 
[2] a) T. A. Brooks, L. H. Hurley, Nat Rev Cancer 2009, 9, $849-861$; b) D. Sun, K. Guo, Y.-J. Shin, Nucleic Acids Res. 2011, 39, 1256 - 1265.

[3] a) S. Balasubramanian, L. H. Hurley, S. Neidle, Nat Rev Drug Discov 2011, 10, 261 - 275; b) H. J. Lipps, D. Rhodes, Trends Cell Biol. 2009, 19, $414-422$.

[4] a) G. W. Collie, G. N. Parkinson, Chem. Lett. Chem. Soc Rev 2011, 40, 5867 - 5892; b) Y. Qin, L. H. Hurley, Biochimie 2008, 90, 1149 - 1171.

[5] S. Cosconati, L. Marinelli, R. Trotta, A. Virno, S. De Tito, R. Romagnoli, B. Pagano, V. Limongelli, C. Giancola, P. G. Baraldi, L. Mayol, E. Novellino, A. Randazzo, J Am Chem. Soc 2010, 132, 6425 - 6433.

[6] a) S. M. Haider, S. Neidle, G. N. Parkinson, Biochimie 2011, 93, 1239 1251 ; b) S. Neidle, FEBS J. 2010, 277, $1118-1125$.

[7] M. Nikan, J. C. Sherman, Angew. Chem. Int. Ed. 2008, 47, 4900 4902.

[8] a) H.-M. So, K. Won, Y. H. Kim, B.-K. Kim, B. H. Ryu, P. S. Na, H. Kim, J.-O. Lee, J Am Chem. Soc 2005, 127, 11906 - 11907; b) C.-L. Hsu, H.-T. Chang, C.-T. Chen, S.-C. Wei, Y.-C. Shiang, C.-C. Huang, Chem. Eur. J. $2011,17,10994-11000$.

[9] a) F. D. Lewis, Y. Wu, L. Zhang, Chem. Commun. 2004, $636-637$; b) J. Jayawickramarajah, D. M. Tagore, L. K. Tsou, A. D. Hamilton, Angew. Chem. Int. Ed. 2007, 46, $7583-7586$.

[10] a) M. Senior, R. A. Jones, K. J. Breslauer, Biochemistry 1988, 27, 3879 - 3885; b) K. M. Guckian, B. A. Schweitzer, R. X. F. Ren, C. J. Sheils, D. C. Tahmassebi, E. T. Kool, J. Am. Chem. Soc. 2000, 122, 2213 - 2222; c) Z. Dogan, R. Paulini, J. A. Rojas Stutz, S. Narayanan, C. Richert, J Am Chem. Soc 2004, 126, $4762-4763$.

[11] R. Lucas, I. Gómez-Pinto, A. Aviñó, J. J. Reina, R. Eritja, C. González, J. C. Morales, J Am Chem. Soc 2011, 133, 1909 - 1916.

[12] R. Lucas, E. Vengut-Climent, I. Gómez-Pinto, A. Aviñó, R. Eritja, C. González, J. C. Morales, Chem. Commun. 2012, 48, 2991 - 2993.

[13] J. D'Onofrio, L. Petraccone, L. Martino, G. Di Fabio, A. Iadonisi, J. Balzarini, C. Giancola, D. Montesarchio, Bioconjugate Chem. 2008, 19, 607 $-616$.

[14] a) R. F. Macaya, P. Schultze, F. W. Smith, J. A. Roe, J. Feigon, Proc Natl Acad Sci USA 1993, 90, 3745 -3749; b) K. Y. Wang, S. McCurdy, R. G. Shea, S. Swaminathan, P. H. Bolton, Biochemistry 1993, 32, 1899 - 1904; c) K. Padmanabhan, K. P. Padmanabhan, J. D. Ferrara, J. E. Sadler, A. Tulinsky, J Biol Chem. 1993, 268, 17651 - 17654; d) J. A. Kelly, J. Feigon, T. O. Yeates, J Mol Biol 1996, 256, $417-422$.

[15] L. Martino, A. Virno, A. Randazzo, A. Virgilio, V. Esposito, C. Giancola, M. Bucci, G. Cirino, L. Mayol, Nucleic Acids Res. 2006, 34, 6653 -6662.

[16] A. De Rache, I. Kejnovska, M. Vorlickova, C. Buess-Herman, Chem. Eur. J. 2012, 18, $4392-4400$.

[17] a) S. R. Nallagatla, B. Heuberger, A. Haque, C. Switzer, J Comb Chem. 2009, 11, 364 -369; b) J. Gros, A. AviÇ_, J. Lopez de La Osa, C. Gonzalez, L. Lacroix, A. Perez, M. Orozco, R. Eritja, J. L. Mergny, Chem. Commun. 2008, 2926 - 2928; c) S. Ogasawara, M. Maeda, Angew. Chem. Int. Ed. 2009, 48, $6671-6674$.

[18] a) T. Coppola, M. Varra, G. Oliviero, A. Galeone, G. D'Isa, L. Mayol, E. Morelli, M. R. Bucci, V. Vellecco, G. Cirino, N. Borbone, Bioorg. Med. Chem. 2008, 16, 8244 - 8253; b) Y. Kasahara, S. Kitadume, K. Morihiro, M. Kuwahara, H. Ozaki, H. Sawai, T. Imanishi, S. Obika, Bioorg. Med. Chem. 
Lett. 2010, 20, 1626 - 1629; c) C. G. Peng, M. J. Damha, Nucleic Acids Res. 2007, 35, 4977 -4988; d) A. Pasternak, F. J. Hernandez, L. M. Rasmussen, B. Vester, J. Wengel, Nucleic Acids Res. 2011, 39, $1155-1164$; e) H. Saneyoshi, S. Mazzini, A. Aviñó, G. Portella, C. Gonzalez, M. Orozco, V. E. Marquez, R. Eritja, Nucleic Acids Res. 2009, 37, 5589 -5601.

[19] a) A. Aviñó, S. Mazzini, R. Ferreira, R. Eritja, Bioorg. Med. Chem. 2010, 18, 7348 - 7356; b) S. Nagatoishi, T. Nojima, B. Juskowiak, S. Takenaka, Angew. Chem. Int. Ed. 2005, 44, 5067 - 5070.

[20] a) Y. Wang, F. Yang, X. Yang, Biosens. Bioelectron. 2010, 25, 1994 1998; b) H. de Puig, S. Federici, S. H. Baxamusa, P. Bergese, K. HamadSchifferli, Small 2011; c) Y. C. Shiang, C. L. Hsu, C. C. Huang, H. T. Chang, Angew. Chem. Int. Ed. 2011, 50, 7660 - 7665.

[21] J. C. Morales, J. J. Reina, I. Díaz, A. Aviñó, P. M. Nieto, R. Eritja, Chem. Eur. J. 2008, 14, 7828 - 7835.

[22] J. D. Puglisi, I. Tinoco, Jr., Methods Enzymol 1989, 180, $304-325$.

[23] I. Smirnov, R. H. Shafer, Biochemistry 2000, 39, $1462-1468$.

[24] G. N. Parkinson, M. P. Lee, S. Neidle, Nature 2002, 417, $876-880$.

[25] A. T. Phan, D. J. Patel, J Am Chem. Soc 2003, 125, $15021-15027$. 
SUPPLEMENTARY INFORMATION

\section{Carbohydrate-DNA interactions at G-quadruplexes: folding and}

\section{stability}

\section{changes by attaching sugars at the 5'-end.}

Irene Gómez-Pinto, Empar Vengut-Climent, Ricardo Lucas, Anna Aviñó, Ramón Eritja, Carlos González*, Juan C. Morales*

\section{Contents}

Figure S1: CD spectra of the carbohydrate-TBA conjugates (5-9).

Figure S2: Native 20\% polyacrylamide gel electrophoresis of carbohydrate-TBA conjugates (5-9), unmodified TBA (1) and 5'-(2-hydroxyethyl)phosphate-TBA (3) S2

Figure S3: Imino region of $1 \mathrm{D}{ }^{1} \mathrm{H}-\mathrm{NMR}$ spectra of carbohydrate-TBA conjugates and assignment of imino proton resonances.

Figure S4: Chemical shifts differences between carbohydrate-TBA conjugates 5-9 and native TBA sequence $\mathbf{1}$.

Figure S5: Average calculated structure of galactose-TBA conjugate 7

Figure S6: Models of maltose-TBA conjugate 7.

Figure S7: Melting curves for TBA control sequences 1-3, carbohydrate-TBA conjugates 4-11 and TBA derivatives 12-13.

Figure S8: First derivative of the melting curves for TBA control sequences $\mathbf{1}$ and $\mathbf{3}$, carbohydrate-TBA conjugates $\mathbf{6 , 9}$ and $\mathbf{1 0}$ and TBA derivative $\mathbf{1 2}$.

Figure S9: ${ }^{1} \mathrm{H}-\mathrm{NMR}$ spectra (Imino region) of $\mathrm{HOCH}_{2} \mathrm{CH}_{2}-\mathrm{OPO}_{2}{ }^{-}$-AGGGTTAGGGT 15. S14

Table S1: Melting temperatures for TBA control sequence $\mathbf{1}$ and carbohydrate-TBA conjugates 6 and 9 at different concentrations.

Table S2: Structurally relevant carbohydrate-DNA NOE contacts for of the carbohydrate-TBA conjugates 5-9.

Table S3: NMR proton assignments (spacer-TBA 3 and carbohydrate-TBA conjugates 5-9). S17

\section{Supplementary Methods}

Synthesis. General information.

$\begin{array}{ll}\text { Preparation and characterization of maltose derivatives 17-20. } & \text { S20 }\end{array}$

$\begin{array}{ll}{ }^{1} \mathrm{H} \text { and }{ }^{13} \mathrm{C} \text {-NMR spectra of compounds 17-20. } & \text { S24 }\end{array}$

$\begin{array}{ll}\text { Synthesis of carbohydrate-DNA conjugates. } & \text { S28 }\end{array}$

$\begin{array}{ll}\text { Thermal denaturation UV measurements } & \text { S28 }\end{array}$

HPLC chromatograms of carbohydrate oligonucleotide conjugates 4-11 and 14. S29 
Maldi-TOF mass spectra of carbohydrate oligonucleotide conjugates 4-11 and 14. S31

NMR spectroscopy and structure calculations.

S32

References.

Figure S1: CD spectra of carbohydrate-TBA conjugates (5-9).

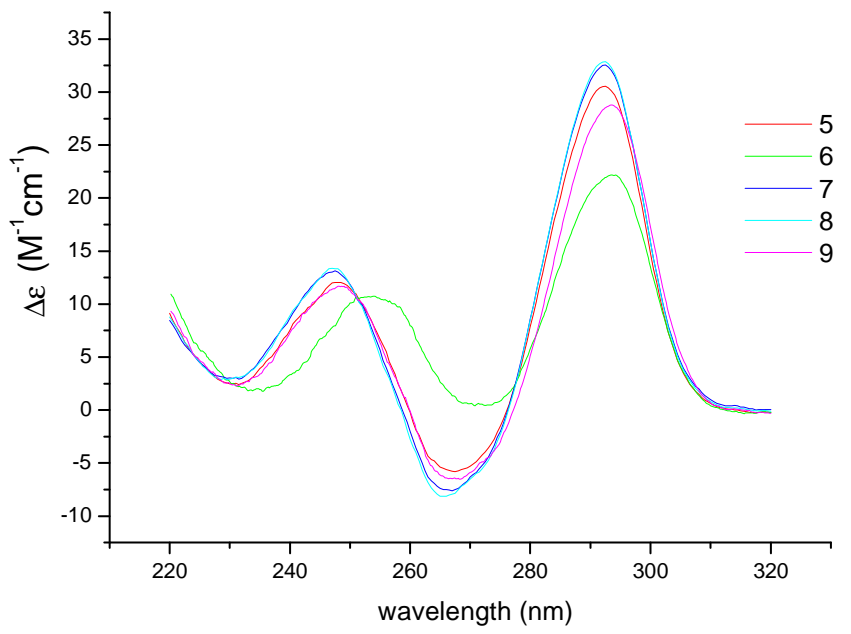

Figure S2: Native 20\% polyacrylamide gel electrophoresis of carbohydrate-TBA conjugates (5-9), unmodified TBA (1) and 5'-(2-hydroxyethyl)phosphate-TBA derivative (3). 
Figure S3: Imino region of $1 \mathrm{D}{ }^{1} \mathrm{H}-\mathrm{NMR}$ spectra of carbohydrate-TBA conjugates and assignment of imino proton resonances.
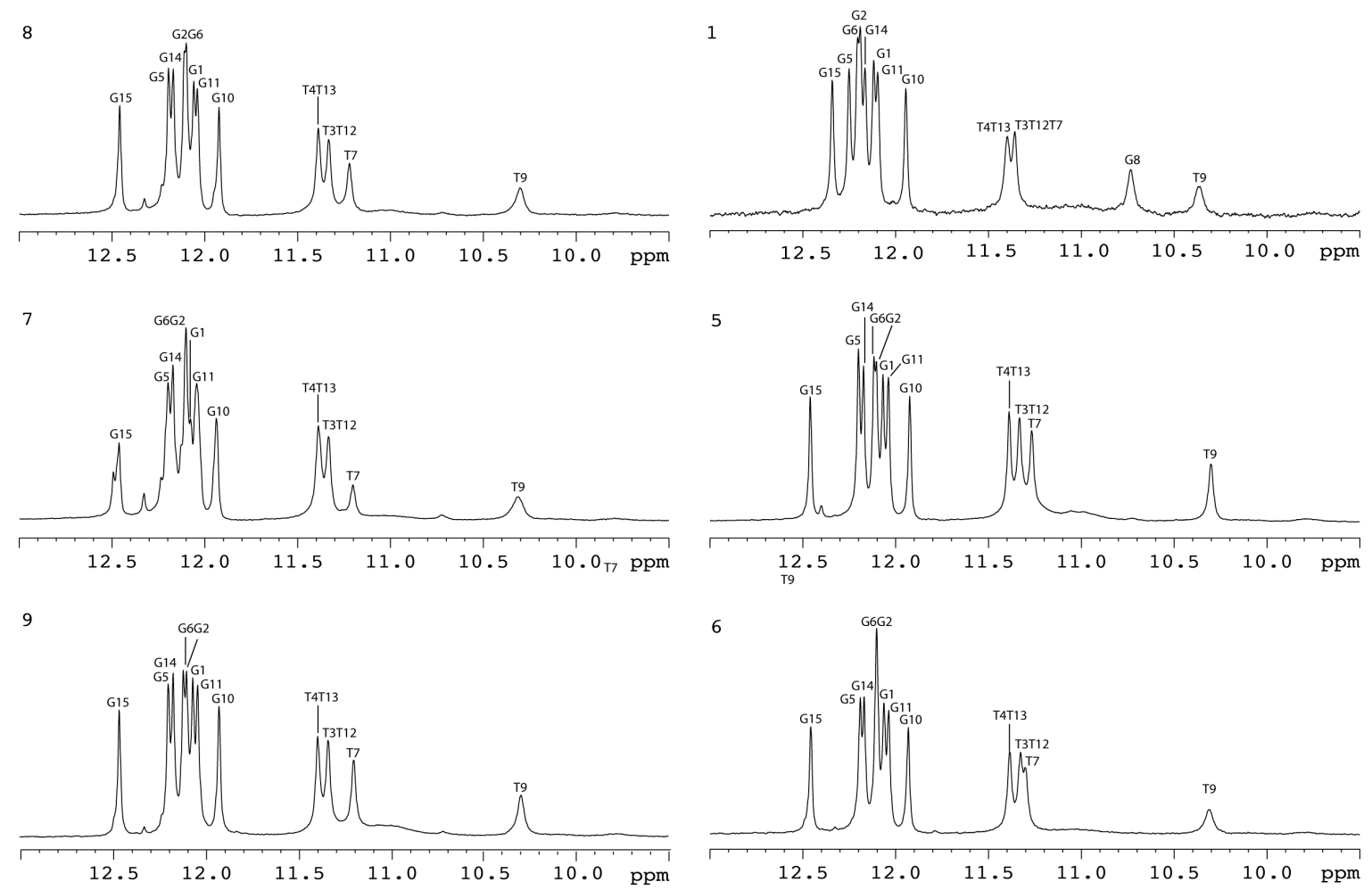
Figure S4. Chemical shifts differences between carbohydrate-TBA conjugates 5-9 and native TBA sequence 1 .
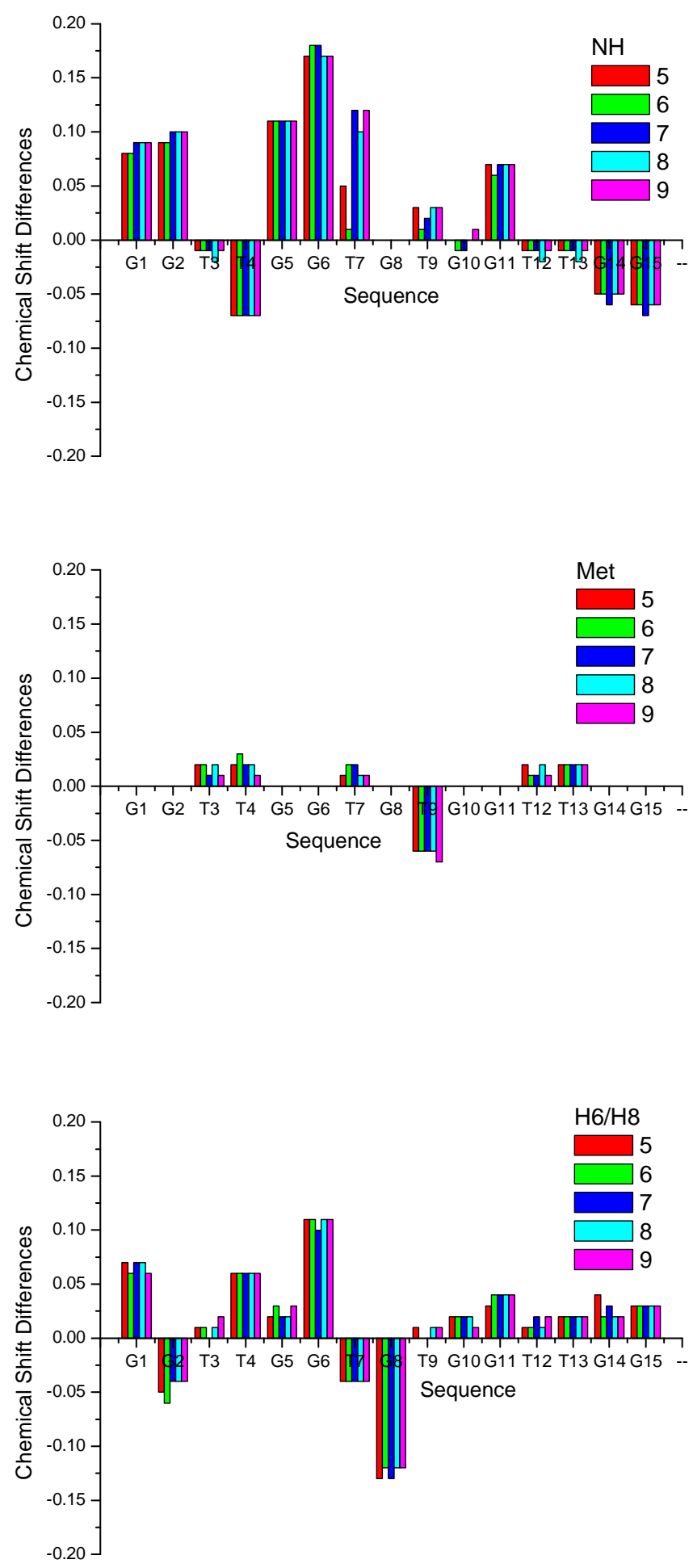

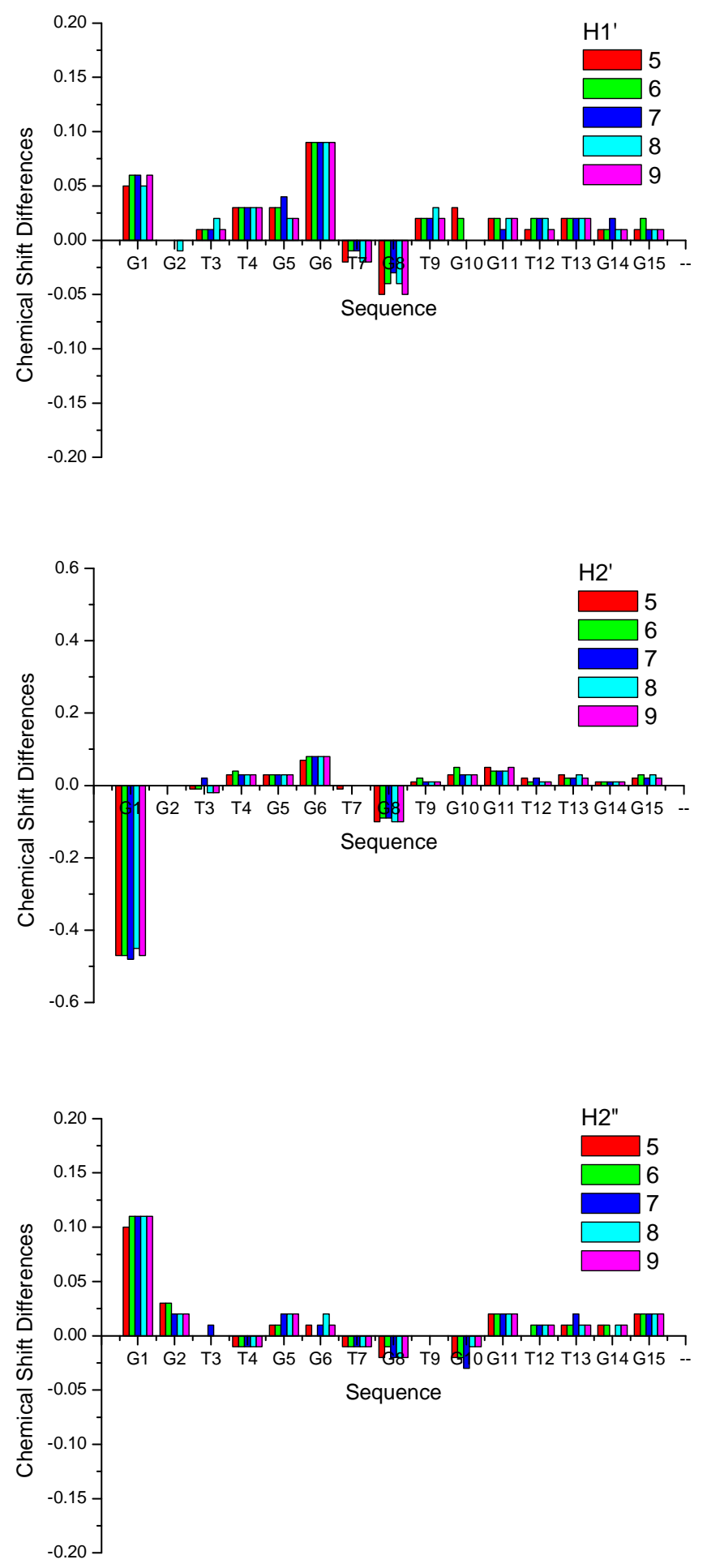
Figure S5: Top view of the average calculated structure of galactose-TBA conjugate 7. Color code: The carbohydrate moiety is shown in red, guanine tetrad in blue and the TGT- loop in green.

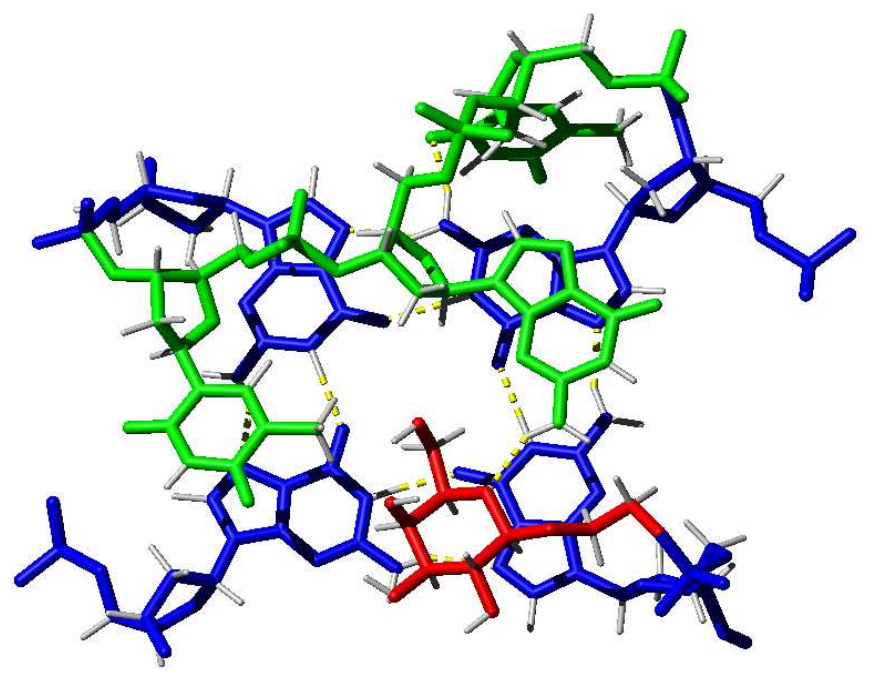


Figure S6: Models of maltose-TBA conjugate 7. A) Side view of the two possible conformations of 7 (left, maltose stacked on the G-tetrad with T9 shifted; right, maltose pointing to the bulk aqueous solution with T9 and G8 stacked on the G-tetrad. B) Top view of $\mathbf{7}$ on the conformation with maltose stacked on the G-tetrad.

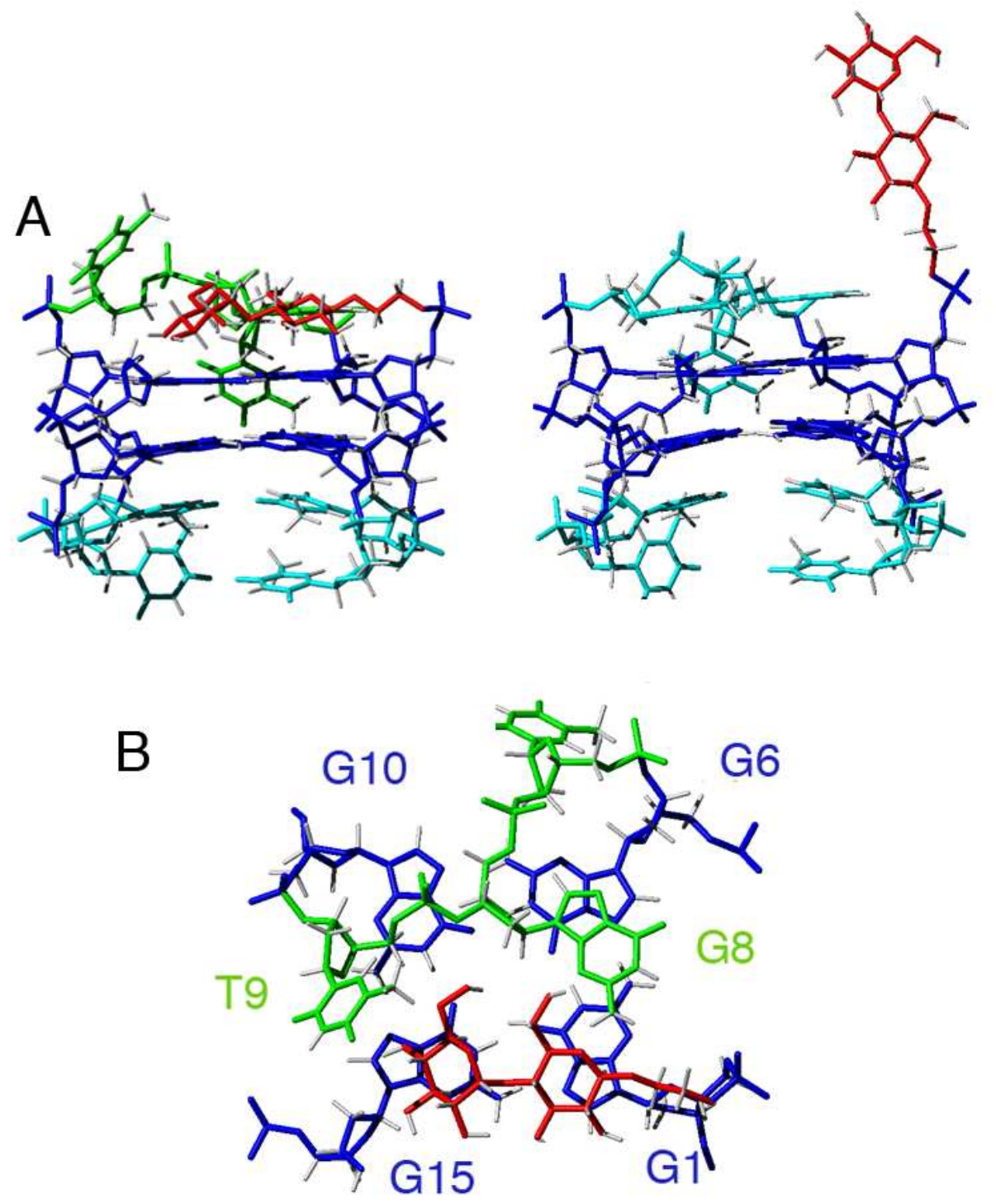


Figure S7: Melting curves for TBA control sequences 1-3, carbohydrate-TBA conjugates 4-11 and TBA derivatives 12-13.
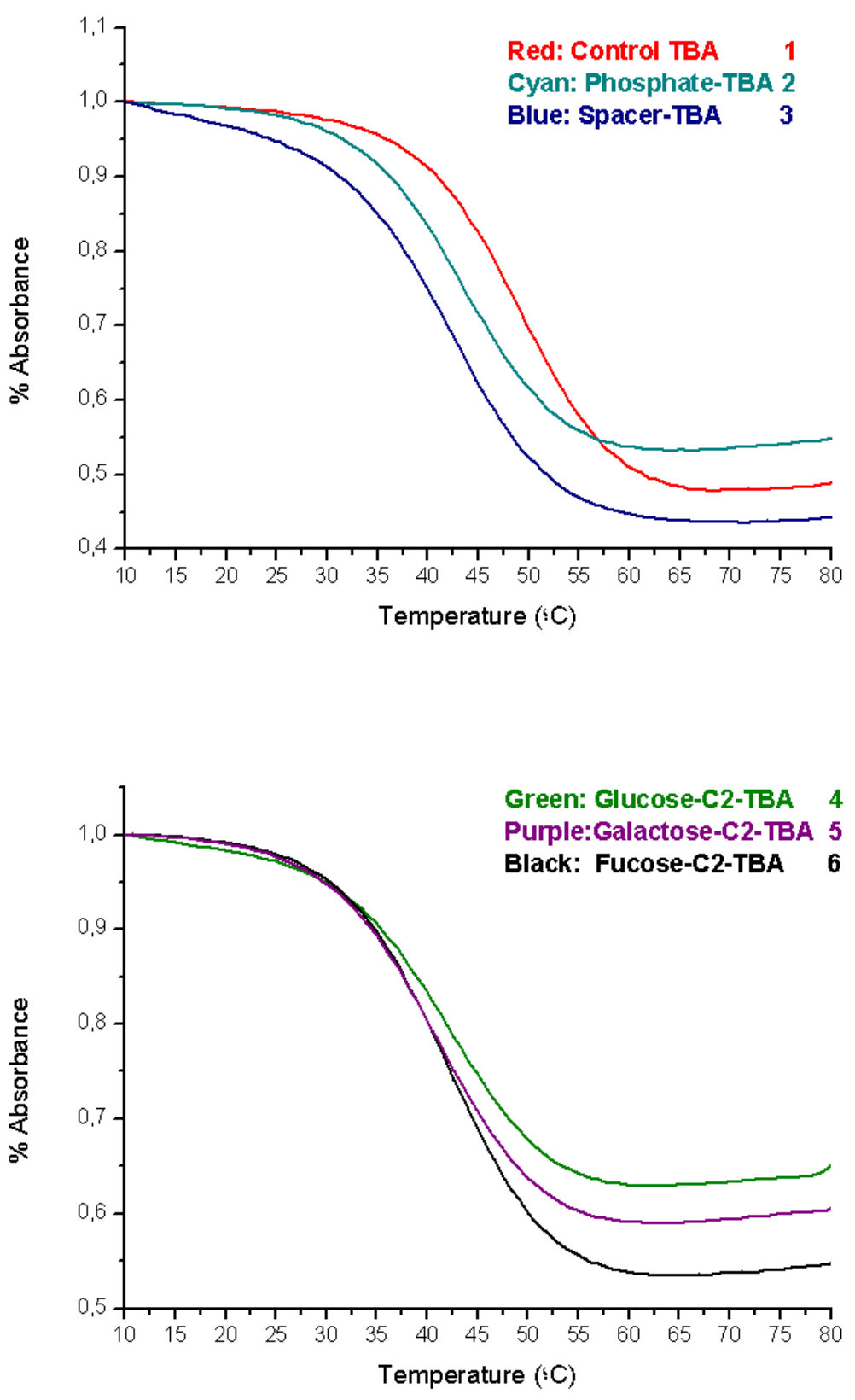

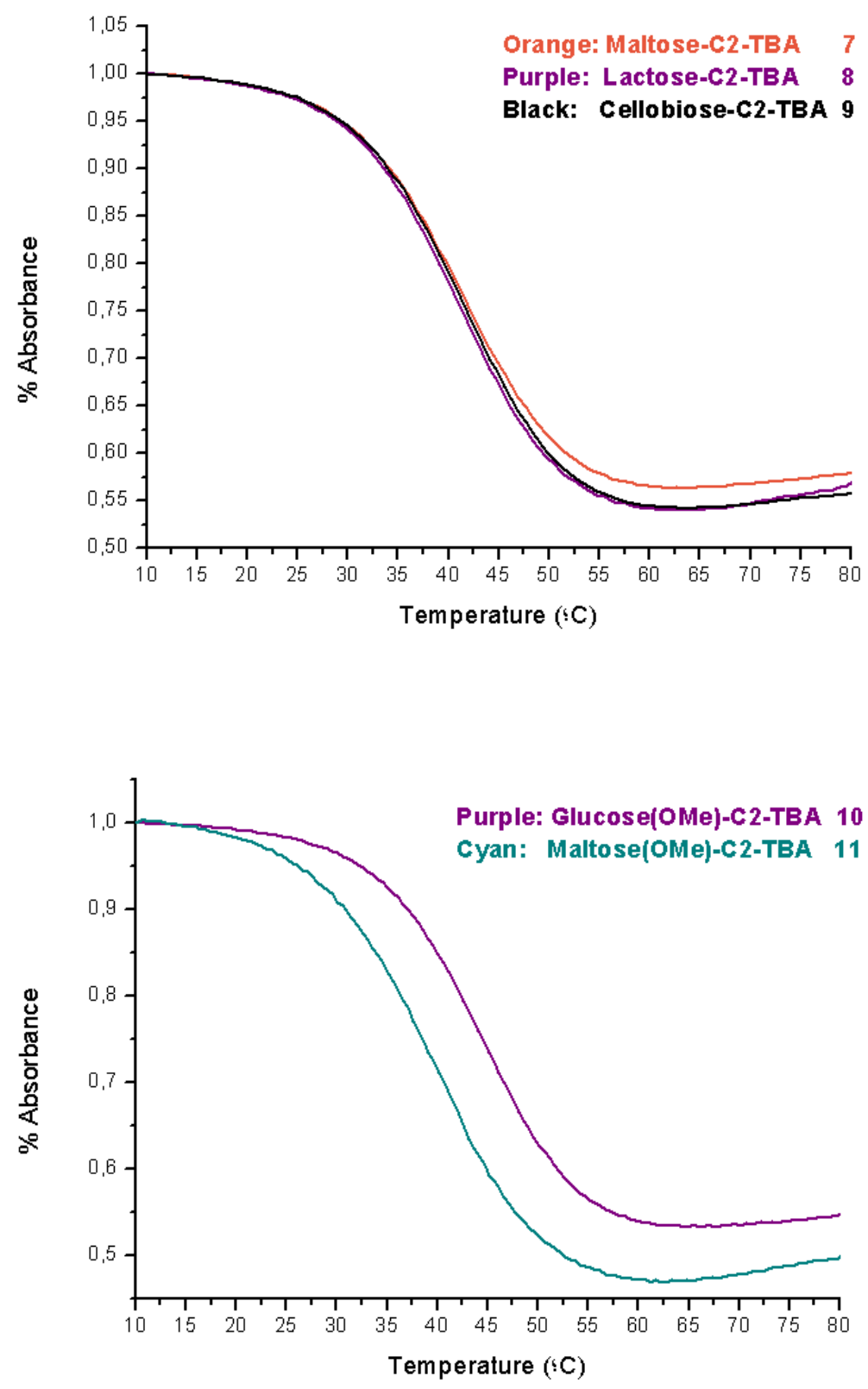


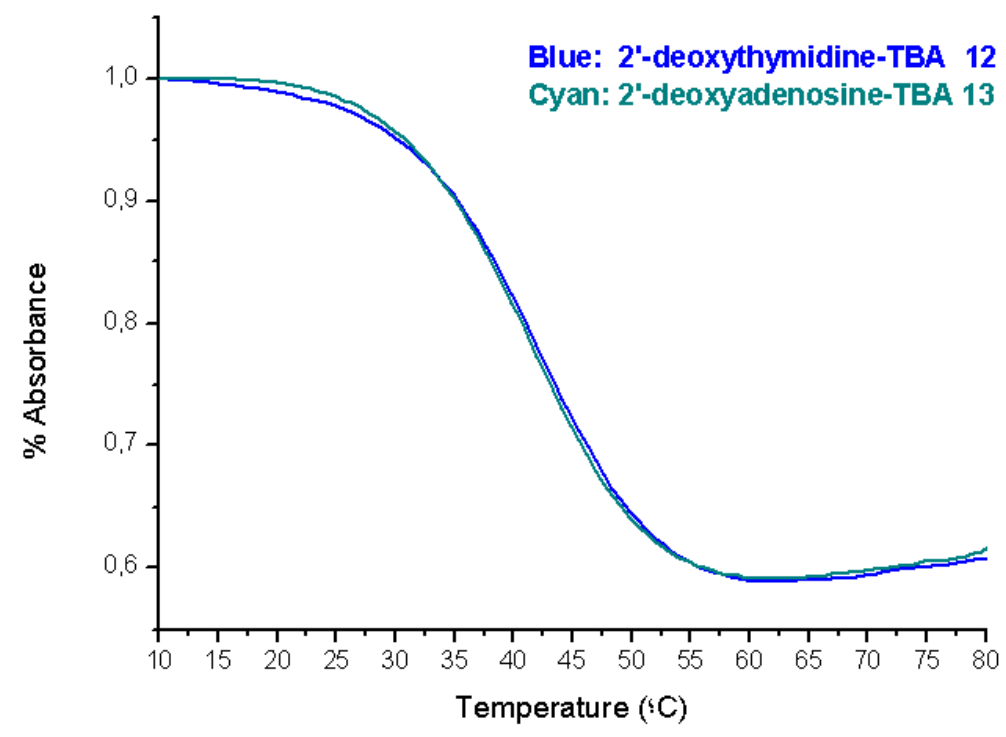


Figure S8: First derivative of the melting curves for TBA control sequences $\mathbf{1}$ and $\mathbf{3}$, carbohydrate-TBA conjugates $\mathbf{6 , 9}$ and $\mathbf{1 0}$ and TBA derivative $\mathbf{1 2}$.
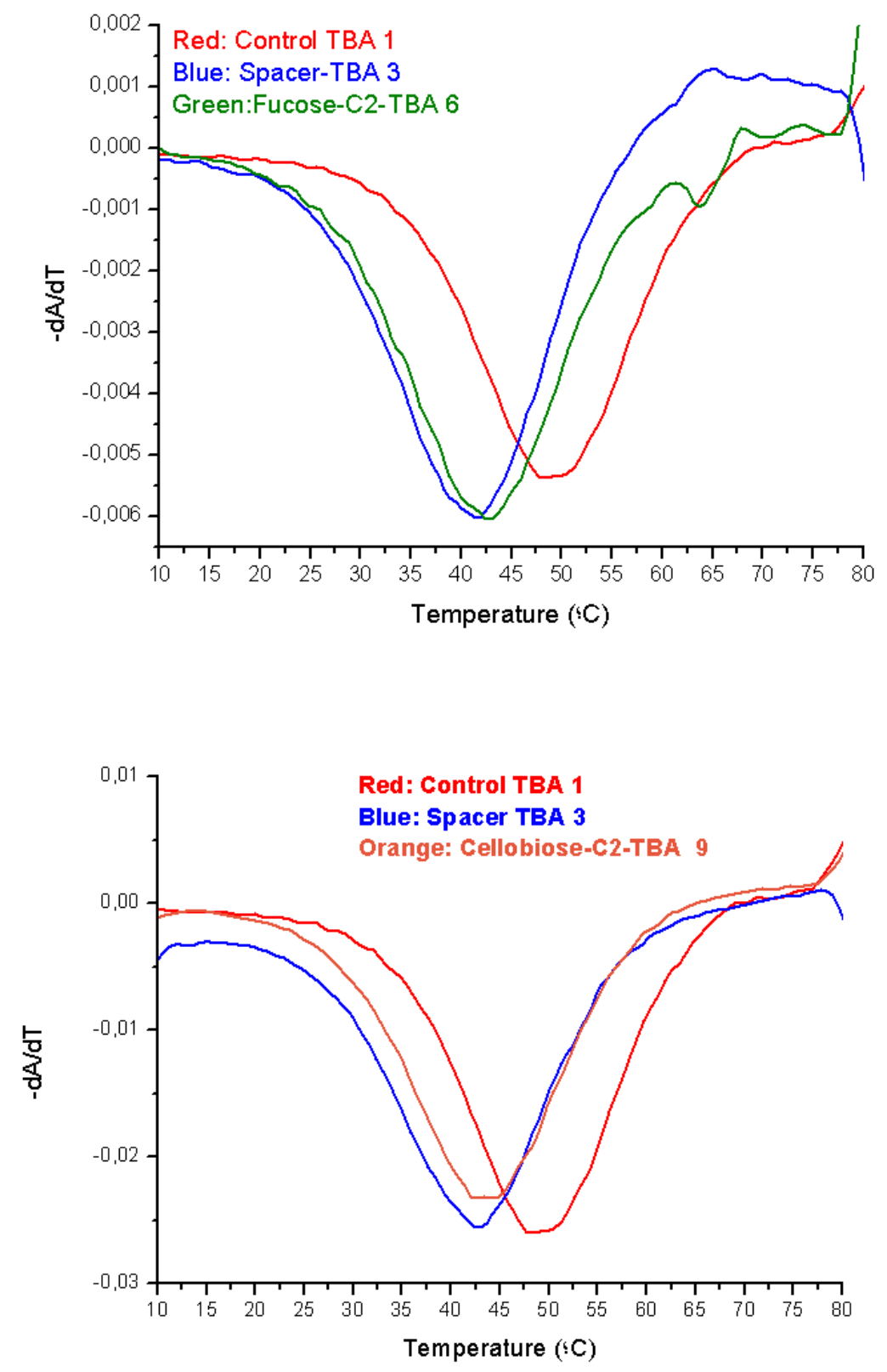

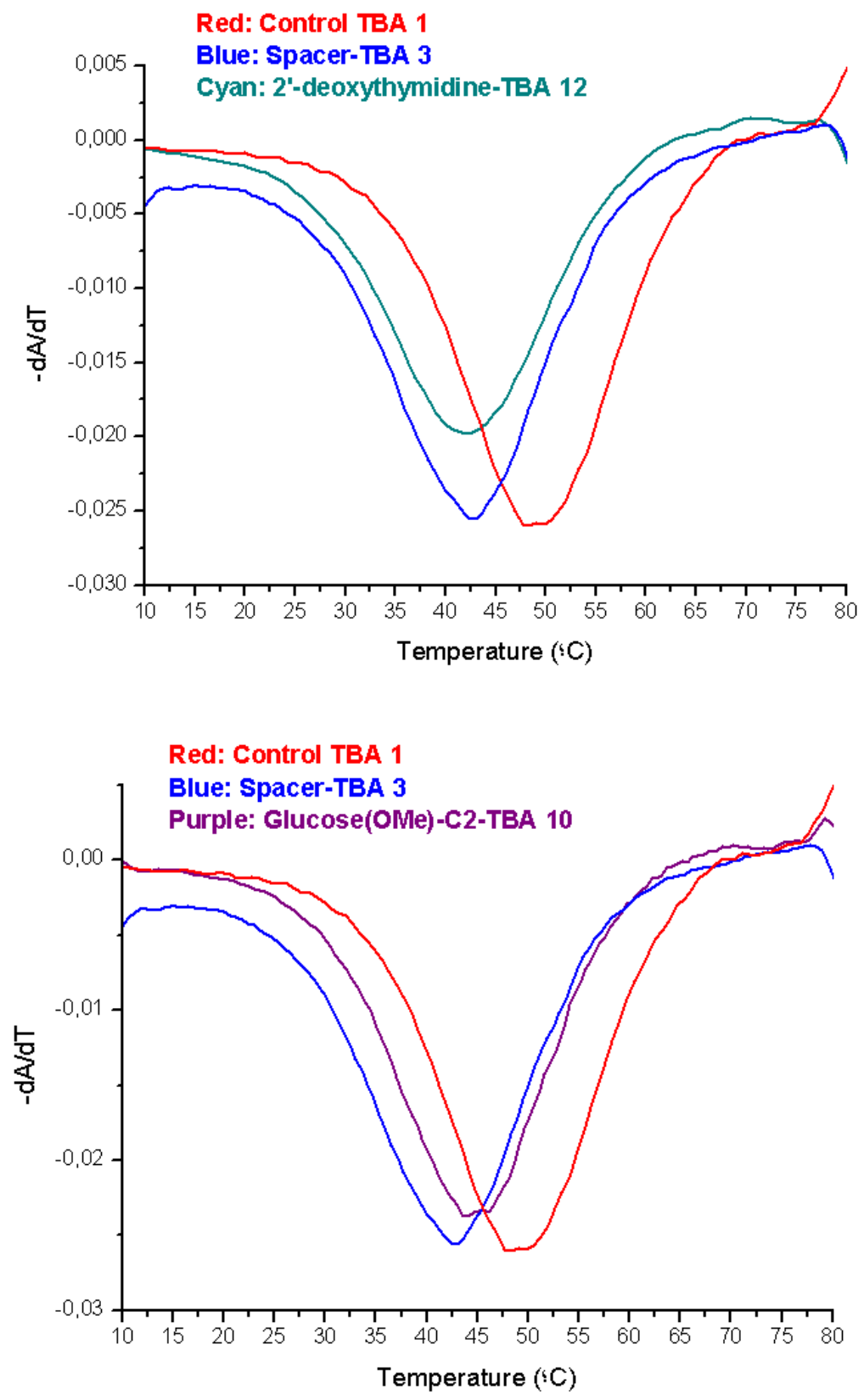
Figure S9: Imino region of $1 \mathrm{D}{ }^{1} \mathrm{H}-\mathrm{NMR}$ spectra of $\mathrm{HO}-\mathrm{CH}_{2}-\mathrm{CH}_{2}-\mathrm{OPO}_{2}{ }^{-}$-

AGGGTTAGGGT conjugate 15.

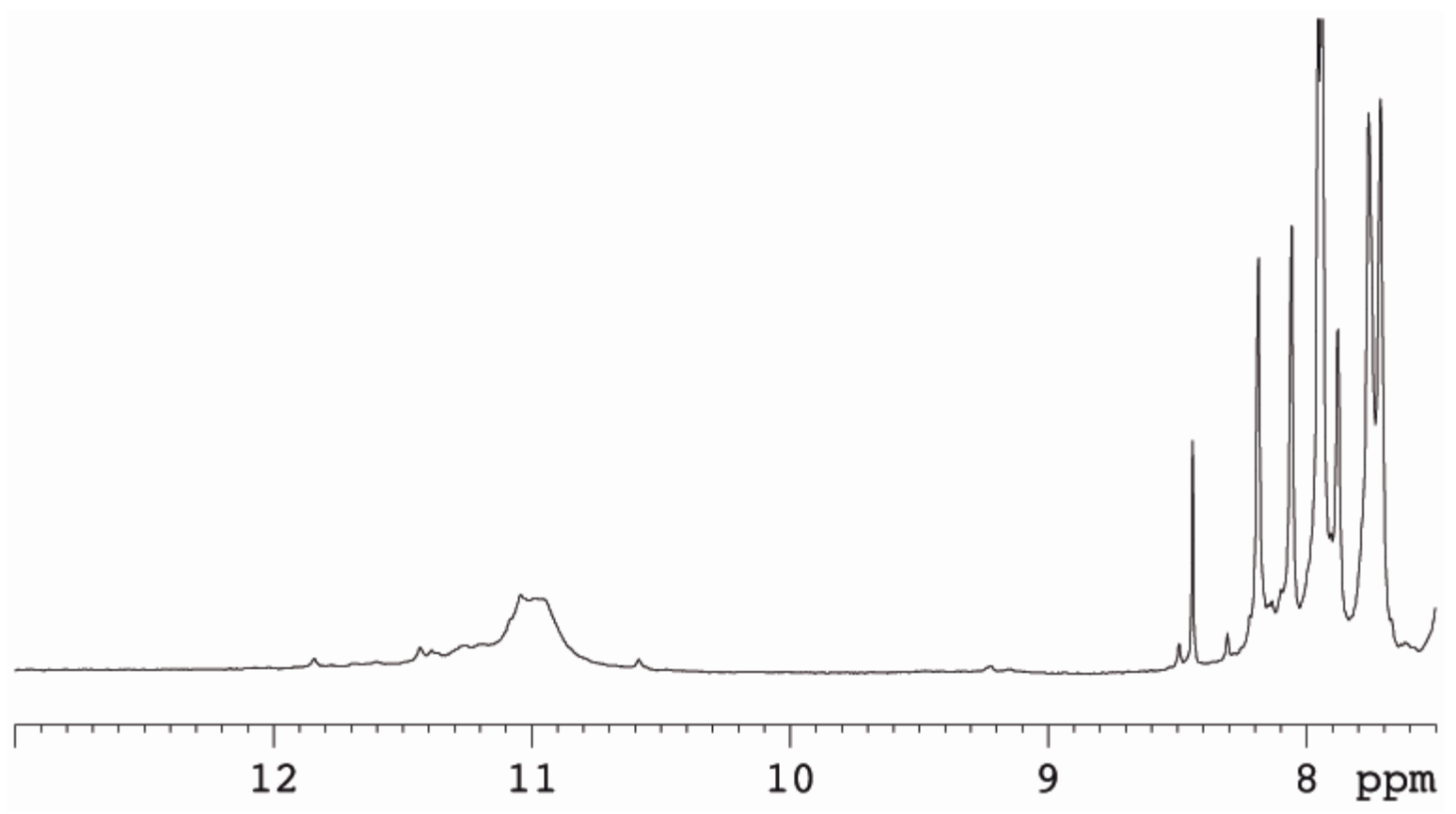


Table S1: Melting temperatures for carbohydrate oligonucleotide conjugates 6 and 9 at different concentrations.

\begin{tabular}{cccc}
\hline \multicolumn{2}{c}{ Fucose-TBA 6 } & \multicolumn{2}{c}{ Cellobiose-TBA 9 } \\
\hline Conc. $(\mathbf{u M})$ & Tm $\left({ }^{\mathbf{o}} \mathbf{C}\right)$ & Conc. $(\mathbf{u M})$ & Tm $\left({ }^{\mathbf{o}} \mathbf{C}\right)$ \\
\hline 2.6 & 41.8 & 2.0 & 40.4 \\
3.1 & 41.8 & 4.0 & 41.8 \\
5.9 & 41.3 & 7.9 & 41.8 \\
8.0 & 42.9 & 8.1 & 41.7 \\
12.1 & 41.2 & 16.0 & 41.5 \\
59.2 & 41.7 & 61.3 & 42.1 \\
\hline
\end{tabular}

Table S2: Structurally relevant carbohydrate-DNA NOE contacts for the carbohydrateTBA conjugates 5-9.

Conjugate 6 (Fucose-TBA)

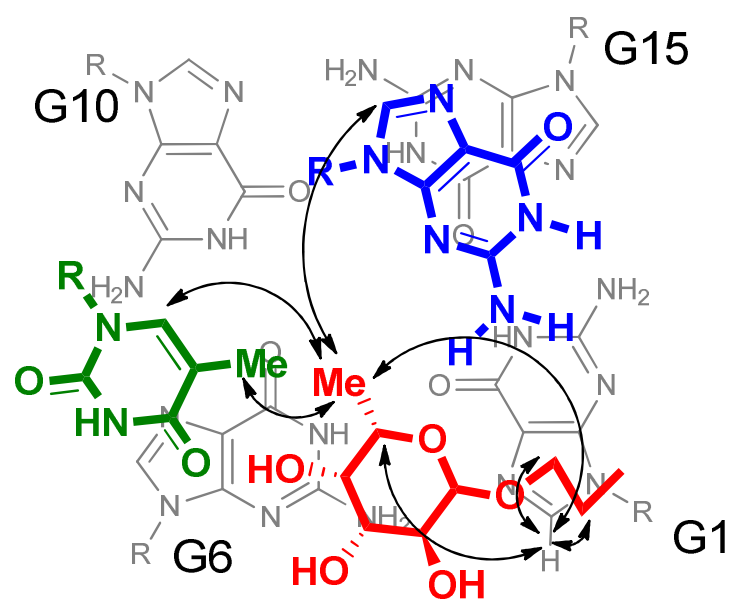




\begin{tabular}{|l|l|l|l|l|}
\hline \multicolumn{5}{|c|}{ Carbohydrate-DNA NOEs } \\
\hline Galactose-TBA 5 & \multicolumn{1}{|c|}{ Fucose-TBA 6 } & \multicolumn{1}{|c|}{ Maltose-TBA 7 } & \multicolumn{1}{|c|}{ Lactose-TBA 8 } & \multicolumn{1}{c|}{ Cellobiose-TBA 9 } \\
\hline G1H8-LinkH1': m & G1H8-Me: w & G1H8-H1: w & G1H8-H1: w & G1H8-H6a: w \\
G1H8-LinkH2': w & G1H8-H5: w & G1H8-H1 (malt2): vw & G1H8-H3: w & G1H8-H6b: w \\
G1H8-H5: m & G1H1'-Me: w & G1H8-H4: m & G1H8-H4/5: m & G1H8-H1: m \\
G1H8-H3: m & G1H8-LinkH1': m & G1H8-H3/5: w & & \\
& G1H8-LinkH2': w & & & \\
\hline & G''H8-Me: w & & G8'H8-H1: vw & \\
& G8'H1'-Me: w & & & \\
\hline & T9H6-Me: w & & & \\
& T9Me-Me:w & & & \\
\hline & G15H1'-Me: vw & & & \\
\hline
\end{tabular}

\begin{tabular}{|c|l|l|l|}
\hline \multicolumn{5}{|c|}{ Carbohydrate-Carbohydrate NOEs } \\
\hline & Carb1-Carb2 & \multicolumn{1}{|c|}{ Carb1-Linker } & \multicolumn{1}{c|}{ G1-Linker } \\
\hline GALACTOSE & & & H8-H1:m \\
H8-H2:w
\end{tabular}

\begin{tabular}{|c|c|c|}
\hline \multicolumn{3}{|c|}{ Fucose-TBA 6, significant NOEs in -TGT- loop } \\
\hline Experimental NOE & Distance in structure of 6 & Distance in native TBA \\
\hline G6 H1-G8 H4': $m$ & 3.6 & 4.1 \\
\hline G6 H1'-T7 H6: $m$ & 3.4 & 4.3 \\
\hline T7 H2'-G8 H8: w & 4.7 & 4.6 \\
\hline G8 H4'-T9 Me: w & 4.6 & 4.9 \\
\hline G8 H1'-T9 Me: w & 3.7 & 3.6 \\
\hline T9 Me-G15 H1: m & 4.0 & 5.0 \\
\hline T9 H1'-G10 H1: w & 5.2 & 5.2 \\
\hline T9 Me-G10 H1: w & 4.2 & 7.1 \\
\hline T9 Me-G15 H1': w & 6.1 & 7.8 \\
\hline T9 H1'-G15 H8: w & 4.4 & 3.8 \\
\hline
\end{tabular}


Table S3: NMR assignments of DNA protons in control sequence (3) and carbohydrate-TBA conjugates $(\mathbf{5 - 9})$ at $\mathrm{T}=5{ }^{\circ} \mathrm{C}(5 \mathrm{mM}$ potassium phosphate, $\mathrm{pH}=7)$. See scheme for protons names.

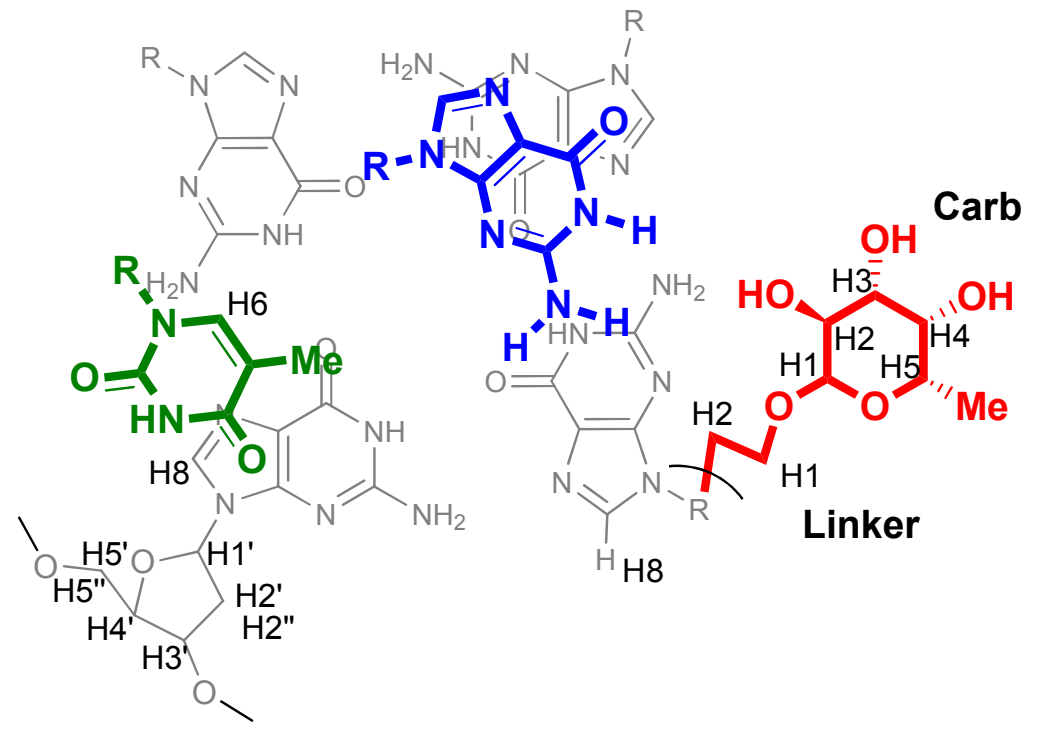

\begin{tabular}{|c|c|c|c|c|c|c|c|c|c|}
\hline Conjugate & & H1' & H2'/H2"' & H3' & H4' & H5'/H5" & Met & H6/H8 & H1/H3 \\
\hline \multirow{8}{*}{3} & G1 & 6.11 & 3.01 & 4.92 & 4.30 & 4.44 & -- & 7.43 & 12.15 \\
\hline & G2 & 6.06 & $3.07 / 2.37$ & 5.19 & 4.44 & 4.30 & -- & 8.23 & 12.2 \\
\hline & T3 & 6.21 & $2.26 / 2.61$ & 4.94 & 4.30 & 4.25 & 2.01 & 7.93 & 11.32 \\
\hline & T4 & 6.09 & $2.07 / 2.69$ & 4.91 & 4.24 & 3.95 & 1.04 & 7.2 & 11.32 \\
\hline & G5 & 6.08 & $3.39 / 2.94$ & 4.89 & 4.44 & $4.32 / 4.28$ & -- & 7.47 & 12.31 \\
\hline & G6 & 5.98 & $2.82 / 2.64$ & 5.14 & 4.46 & $4.32 / 4.25$ & -- & 7.72 & 12.29 \\
\hline & T7 & 6.53 & $2.53 / 2.65$ & 4.88 & 4.46 & $4.32 / 4.25$ & 2.01 & 7.96 & 11.32 \\
\hline & G8 & 5.8 & $2.00 / 2.34$ & 4.80 & 4.00 & $4.14 / 4.04$ & -- & 7.49 & 10.71 \\
\hline \multirow{7}{*}{$\begin{array}{c}\mathrm{HO}-\mathrm{CH}_{2-}^{-} \\
\mathrm{CH}_{2^{-}} \\
\mathrm{OPO}_{2^{-}} \\
\mathrm{TBA}\end{array}$} & T9 & 5.85 & $1.99 / 2.44$ & 4.65 & 3.81 & $3.58 / 3.04$ & 1.83 & 7.29 & 10.33 \\
\hline & G10 & 6.09 & $3.76 / 2.95$ & 4.94 & 4.29 & -- & -- & 7.47 & 11.93 \\
\hline & G11 & 6.04 & $3.01 / 2.35$ & 5.17 & 4.42 & 4.30 & -- & 8.26 & 12.11 \\
\hline & T12 & 6.21 & $2.25 / 2.61$ & 4.93 & 4.30 & 4.25 & 2.01 & 7.93 & 11.32 \\
\hline & T13 & 6.14 & $2.11 / 2.76$ & 4.93 & 4.32 & 3.95 & 0.99 & 7.27 & 11.32 \\
\hline & G14 & 6.11 & $3.53 / 3.00$ & 4.95 & 4.45 & $4.30 / 4.21$ & -- & 7.5 & 12.12 \\
\hline & G15 & 6.19 & $2.72 / 2.46$ & 4.82 & 4.27 & 4.20 & -- & 8.11 & 12.4 \\
\hline \multirow{7}{*}{5} & G1 & 6.06 & $3.48 / 2.91$ & -- & 4.30 & -- & -- & 7.36 & 12.07 \\
\hline & G2 & 6.06 & $3.07 / 2.34$ & 5.18 & 4.43 & 4.29 & -- & 8.28 & 12.11 \\
\hline & T3 & 6.20 & $2.27 / 2.61$ & 4.93 & 4.28 & 4.23 & 1.99 & 7.92 & 11.33 \\
\hline & T4 & 6.06 & $2.04 / 2.70$ & 4.90 & 4.29 & 3.93 & 1.02 & 7.14 & 11.39 \\
\hline & G5 & 6.05 & $3.36 / 2.93$ & 4.87 & 4.42 & $4.31 / 4.23$ & -- & 7.45 & 12.20 \\
\hline & G6 & 5.89 & $2.75 / 2.63$ & 5.12 & 4.42 & 4.25 & -- & 7.61 & 12.12 \\
\hline & T7 & 6.55 & $2.54 / 2.66$ & 4.87 & 4.48 & $4.34 / 4.24$ & 2.00 & 8.00 & 11.27 \\
\hline \multirow{8}{*}{$\begin{array}{c}\beta-\mathrm{D}- \\
\text { galactose- } \\
\mathrm{CH}_{2}-\mathrm{CH}_{2}^{-} \\
\mathrm{OPO}_{2}^{-} \\
\mathrm{TBA}\end{array}$} & G8 & 5.85 & $2.10 / 2.36$ & 4.79 & 4.01 & $4.15 / 4.09$ & -- & 7.62 & -- \\
\hline & T9 & 5.83 & $1.98 / 2.44$ & 4.63 & 3.89 & $3.57 / 2.97$ & 1.89 & 7.28 & 10.30 \\
\hline & G10 & 6.06 & $3.73 / 2.97$ & -- & -- & -- & -- & 7.45 & 11.93 \\
\hline & G11 & 6.02 & $2.96 / 2.33$ & 5.18 & 4.40 & $4.28 / 4.23$ & -- & 8.23 & 12.04 \\
\hline & T12 & 6.20 & $2.23 / 2.61$ & 4.93 & 4.28 & 4.23 & 1.99 & 7.92 & 11.33 \\
\hline & T13 & 6.12 & $2.08 / 2.75$ & 4.91 & 4.30 & 3.93 & 0.97 & 7.25 & 11.33 \\
\hline & G14 & 6.10 & $3.52 / 2.99$ & 4.93 & 4.42 & 4.29 & -- & 7.46 & 12.17 \\
\hline & G15 & 6.18 & $2.70 / 2.44$ & 4.79 & 4.29 & 4.18 & -- & 8.08 & 12.46 \\
\hline & G1 & 6.05 & $3.48 / 2.90$ & -- & 4.29 & -- & -- & 7.37 & 12.07 \\
\hline & G2 & 6.06 & $3.07 / 2.34$ & 5.15 & 4.43 & 4.28 & -- & 8.29 & 12.11 \\
\hline
\end{tabular}




\begin{tabular}{|c|c|c|c|c|c|c|c|c|c|}
\hline \multirow{7}{*}{6} & T3 & 6.20 & $2.27 / 2.61$ & 4.93 & 4.28 & 4.23 & 1.99 & 7.92 & 11.33 \\
\hline & T4 & 6.06 & $2.03 / 2.70$ & 4.90 & 4.29 & 3.93 & 1.01 & 7.14 & 11.39 \\
\hline & G5 & 6.05 & $3.36 / 2.93$ & 4.88 & 4.41 & $4.30 / 4.23$ & -- & 7.44 & 12.20 \\
\hline & G6 & 5.89 & $2.74 / 2.62$ & 5.11 & 4.41 & 4.29 & -- & 7.61 & 12.11 \\
\hline & T7 & 6.54 & $2.53 / 2.66$ & 4.86 & 4.47 & $4.33 / 4.25$ & 1.99 & 8.00 & 11.31 \\
\hline & G8 & 5.84 & $2.09 / 2.35$ & 4.79 & 4.01 & $4.14 / 4.08$ & --- & 7.61 & -- \\
\hline & T9 & 5.83 & $1.97 / 2.44$ & 4.64 & 3.90 & $3.56 / 2.98$ & 1.89 & 7.29 & 10.32 \\
\hline \multirow{6}{*}{$\begin{array}{c}\beta-\mathrm{L}- \\
\text { fucose- } \\
\mathrm{CH}_{2}-\mathrm{CH}_{2-}^{-} \\
\mathrm{OPO}_{2}^{-}- \\
\mathrm{TBA}^{-}\end{array}$} & G10 & 6.07 & $3.71 / 2.97$ & -- & -- & -- & -- & 7.45 & 11.94 \\
\hline & G11 & 6.02 & $2.97 / 2.33$ & 5.15 & 4.40 & $4.32 / 4.26$ & -- & 8.22 & 12.05 \\
\hline & T12 & 6.19 & $2.24 / 2.60$ & 4.93 & 4.28 & 4.23 & 2.00 & 7.92 & 11.33 \\
\hline & T13 & 6.12 & $2.09 / 2.75$ & 4.91 & 4.29 & 3.93 & 0.97 & 7.25 & 11.33 \\
\hline & G14 & 6.10 & $3.52 / 2.99$ & 4.93 & 4.44 & 4.28 & -- & 7.48 & 12.17 \\
\hline & G15 & 6.17 & $2.69 / 2.44$ & 4.80 & 4.25 & 4.18 & -- & 8.08 & 12.46 \\
\hline \multirow{8}{*}{7} & G1 & 6.05 & $3.49 / 2.90$ & -- & 4.28 & -- & -- & 7.36 & 12.06 \\
\hline & G2 & 6.06 & $3.07 / 2.35$ & 5.16 & 4.43 & 4.28 & -- & 8.27 & 12.10 \\
\hline & T3 & 6.20 & $2.24 / 2.60$ & 4.93 & 4.29 & 4.23 & 2.00 & 7.93 & 11.33 \\
\hline & T4 & 6.06 & $2.04 / 2.70$ & 4.90 & 4.29 & 3.92 & 1.02 & 7.14 & 11.39 \\
\hline & G5 & 6.04 & $3.36 / 2.92$ & 4.87 & 4.43 & 4.31 & -- & 7.45 & 12.20 \\
\hline & G6 & 5.89 & $2.74 / 2.63$ & 5.12 & 4.41 & 4.29 & -- & 7.62 & 12.11 \\
\hline & $\mathbf{T 7}$ & 6.54 & $2.53 / 2.66$ & 4.87 & 4.48 & $4.34 / 4.25$ & 2.00 & 8.00 & 11.20 \\
\hline & G8 & 5.83 & $2.09 / 2.36$ & 4.80 & 4.01 & $4.13 / 4.09$ & -- & 7.62 & -- \\
\hline \multirow{7}{*}{$\begin{array}{c}\beta-\mathrm{D}- \\
\text { maltose- } \\
\mathrm{CH}_{2}-\mathrm{CH}_{2}^{-} \\
\mathrm{OPO}_{2}^{-}- \\
\mathrm{TBA}^{-}\end{array}$} & T9 & 5.83 & $1.98 / 2.44$ & 4.64 & 3.89 & $3.56 / 2.99$ & 1.89 & 7.29 & 10.31 \\
\hline & G10 & 6.09 & $3.73 / 2.98$ & 4.94 & -- & -- & --- & 7.45 & 11.94 \\
\hline & G11 & 6.03 & $2.97 / 2.33$ & 5.16 & 4.40 & 4.29 & -- & 8.22 & 12.04 \\
\hline & T12 & 6.19 & $2.23 / 2.60$ & 4.93 & 4.31 & -- & 2.00 & 7.91 & 11.33 \\
\hline & T13 & 6.12 & $2.09 / 2.74$ & 4.92 & 4.30 & 3.93 & 0.97 & 7.25 & 11.33 \\
\hline & G14 & 6.09 & $3.52 / 3.00$ & 4.93 & 4.43 & $4.38 / 4.28$ & -- & 7.47 & 12.18 \\
\hline & G15 & 6.18 & $2.70 / 2.44$ & 4.80 & 4.25 & 4.19 & -- & 8.08 & 12.47 \\
\hline \multirow{8}{*}{8} & G1 & 6.06 & $3.46 / 2.90$ & -- & 4.29 & -- & -- & 7.36 & 12.06 \\
\hline & G2 & 6.07 & $3.07 / 2.35$ & 5.16 & 4.43 & 4.29 & -- & 8.27 & 12.10 \\
\hline & T3 & 6.19 & $2.28 / 2.61$ & 4.93 & 4.28 & 4.23 & 1.99 & 7.92 & 11.34 \\
\hline & T4 & 6.06 & $2.04 / 2.70$ & 4.91 & 4.29 & 3.93 & 1.02 & 7.14 & 11.39 \\
\hline & G5 & 6.06 & $3.36 / 2.92$ & 4.87 & 4.41 & $4.31 / 4.23$ & -- & 7.45 & 12.2 \\
\hline & G6 & 5.89 & $2.74 / 2.62$ & 5.12 & 4.42 & 4.29 & -- & 7.61 & 12.12 \\
\hline & T7 & 6.55 & $2.53 / 2.66$ & 4.86 & 4.48 & $4.34 / 4.25$ & 1.99 & 8.00 & 11.22 \\
\hline & G8 & 5.84 & $2.10 / 2.36$ & 4.79 & 4.01 & $4.15 / 4.09$ & -- & 7.61 & -- \\
\hline \multirow{7}{*}{$\begin{array}{c}\beta-\mathrm{D}- \\
\text { lactose- } \\
\mathrm{CH}_{2}-\mathrm{CH}_{2}^{-} \\
\mathrm{OPO}_{2}^{-}- \\
\mathrm{TBA}\end{array}$} & T9 & 5.82 & $1.98 / 2.44$ & 4.64 & 3.89 & $3.57 / 2.97$ & 1.89 & 7.28 & 10.30 \\
\hline & G10 & 6.09 & $3.73 / 2.96$ & -- & -- & -- & --- & 7.45 & 11.93 \\
\hline & G11 & 6.02 & $2.97 / 2.33$ & 5.17 & 4.40 & $4.29 / 4.24$ & -- & 8.22 & 12.04 \\
\hline & T12 & 6.19 & $2.24 / 2.60$ & 4.93 & 4.28 & 4.23 & 1.99 & 7.92 & 11.34 \\
\hline & T13 & 6.12 & $2.08 / 2.75$ & 4.91 & 4.30 & 3.93 & 0.97 & 7.25 & 11.34 \\
\hline & G14 & 6.10 & $3.52 / 2.99$ & 4.93 & 4.43 & 4.29 & -- & 7.48 & 12.17 \\
\hline & G15 & 6.18 & $2.69 / 2.44$ & 4.79 & 4.29 & 4.19 & -- & 8.08 & 12.46 \\
\hline \multirow{9}{*}{9} & G1 & 6.05 & $3.48 / 2.90$ & -- & 4.29 & -- & -- & 7.37 & 12.06 \\
\hline & G2 & 6.06 & $3.07 / 2.35$ & 5.16 & 4.43 & 4.28 & -- & 8.27 & 12.10 \\
\hline & T3 & 6.20 & $2.28 / 2.61$ & 4.92 & 4.28 & 4.22 & 2.00 & 7.91 & 11.33 \\
\hline & T4 & 6.06 & $2.04 / 2.70$ & 4.90 & 4.29 & 3.93 & 1.03 & 7.14 & 11.39 \\
\hline & G5 & 6.06 & $3.36 / 2.92$ & 4.87 & 4.42 & $4.32 / 4.23$ & -- & 7.44 & 12.20 \\
\hline & G6 & 5.89 & $2.74 / 2.63$ & 5.12 & 4.41 & 4.32 & -- & 7.61 & 12.12 \\
\hline & T7 & 6.55 & $2.53 / 2.66$ & 4.87 & 4.48 & $4.34 / 4.25$ & 2.00 & 8.00 & 11.20 \\
\hline & G8 & 5.85 & $2.10 / 2.36$ & 4.80 & 4.01 & $4.15 / 4.09$ & -- & 7.61 & -- \\
\hline & T9 & 5.83 & $1.98 / 2.44$ & 4.64 & 3.89 & $3.56 / 2.97$ & 1.90 & 7.28 & 10.30 \\
\hline \multirow{5}{*}{$\begin{array}{c}\beta-\mathrm{D}- \\
\text { cellobiose- } \\
\mathrm{CH}_{2}-\mathrm{CH}_{2}^{-} \\
\mathrm{OPO}_{2}^{-}-\end{array}$} & G10 & 6.09 & $3.73 / 2.96$ & -- & -- & -- & -- & 7.46 & 11.92 \\
\hline & G11 & 6.02 & $2.96 / 2.33$ & 5.15 & 4.40 & $4.32 / 4.27$ & -- & 8.22 & 12.04 \\
\hline & T12 & 6.20 & $2.24 / 2.60$ & 4.92 & 4.28 & 4.23 & 2.00 & 7.91 & 11.33 \\
\hline & T13 & 6.12 & $2.09 / 2.75$ & 4.90 & 4.29 & 3.93 & 0.97 & 7.25 & 11.33 \\
\hline & G14 & 6.10 & $3.52 / 2.99$ & 4.93 & 4.45 & $4.38 / 4.30$ & -- & 7.48 & 12.17 \\
\hline
\end{tabular}


TBA

G15

6.18

$2.70 / 2.44$

4.81

4.25

4.19

8.08

12.46

Table S3b: NMR assignment of DNA protons of the second species

\begin{tabular}{|l|c|c|c|c|c|c|c|c|}
\hline Conjugate & Native & H1' & H2'/H2' & H3' & H4' & H5'/H5' & Met & H6/H8 \\
\hline \multirow{4}{*}{7} & G6 & 5.96 & $2.80 / 2.62$ & 5.12 & 4.46 & -- & -- & 7.71 \\
\cline { 2 - 9 } & T7 & 6.51 & $2.52 / 2.63$ & 4.87 & 4.45 & -- & 1.99 & 7.94 \\
\cline { 2 - 9 } & G8 & 5.79 & $1.99 / 2.33$ & -- & -- & -- & -- & 7.48 \\
\hline \multirow{4}{*}{} & G6 & 5.97 & $2.81 / 2.62$ & -- & -- & -- & -- & 7.71 \\
\cline { 2 - 9 } & T7 & 6.51 & $2.52 / 2.63$ & -- & -- & -- & 2.00 & 7.95 \\
\cline { 2 - 9 } & G8 & 5.79 & $1.99 / 2.33$ & -- & -- & -- & -- & 7.49 \\
\hline \multirow{3}{*}{9} & G6 & 5.97 & $2.81 / 2.62$ & -- & -- & -- & -- & 7.71 \\
\cline { 2 - 9 } & T7 & 6.52 & $2.52 / 2.63$ & -- & -- & -- & 2.00 & 7.94 \\
\cline { 2 - 9 } & G8 & 5.79 & $1.99 / 2.34$ & -- & -- & -- & -- & 7.49 \\
\hline
\end{tabular}

Table S3c: NMR assignment of carbohydrate protons of conjugates 5 to 9

\begin{tabular}{|c|c|c|c|c|c|c|c|c|}
\hline Conjugate & H1 & H2 & H3 & H4 & H5 & $\begin{array}{c}\text { H6a/ } \\
\text { H6b }\end{array}$ & H6a/ H6b & Me \\
\hline $\mathbf{5}$ & 4.38 & 3.50 & 3.59 & 3.84 & 3.61 & -- & & \\
\hline $\mathbf{6}$ & 4.35 & 3.43 & 3.55 & 3.64 & 3.68 & & & 1.18 \\
\hline $\mathbf{7}$ & $4.46 / 5.30$ & $3.28 / 3.51$ & $3.68 / 3.66$ & $3.52 / 3.38$ & $3.68 / 3.69$ & $3.85 /--$ & $3.82 / 3.76$ & \\
\hline $\mathbf{8}$ & $4.50 / 4.39$ & $3.31 / 3.52$ & $3.59 / 3.66$ & $3.53 / 3.70$ & $3.53 / 3.66$ & $3.93 / 3.75$ & $3.90 / 3.75$ & \\
\hline $\mathbf{9}$ & $4.47 / 4.44$ & $3.29 / 3.26$ & $3.53 / 3.47$ & $3.49 / 3.58$ & $3.49 / 3.45$ & $3.89 / 3.74$ & $3.87 / 3.69$ & \\
\hline
\end{tabular}




\section{Supplementary Methods}

\section{Synthesis. General information.}

All chemicals were obtained from chemical suppliers and used without further purification, unless otherwise noted. All reactions were monitored by TLC on precoated Silica-Gel 60 plates F254, and detected by heating with Mostain (500 ml of 10\% $\mathrm{H}_{2} \mathrm{SO}_{4}, 25 \mathrm{~g}$ of $\left.\left(\mathrm{NH}_{4}\right)_{6} \mathrm{Mo}_{7} \mathrm{O}_{24} \bullet 4 \mathrm{H}_{2} \mathrm{O}, 1 \mathrm{~g} \mathrm{Ce}\left(\mathrm{SO}_{4}\right)_{2} \bullet 4 \mathrm{H}_{2} \mathrm{O}\right)$. Products were purified by flash chromatography with silica gel60 (200-400 mesh).

NMR spectra were recorded on either a Bruker AVANCE 300 or ARX 400 or Bruker Advance DRX $500 \mathrm{MHz}$ [300 or $400 \mathrm{MHz}(1 \mathrm{H}), 75$ or $100\left({ }^{13} \mathrm{C}\right)$, at room temperature for solutions in $\mathrm{CDCl}_{3}, \mathrm{D}_{2} \mathrm{O}$ or $\mathrm{CD}_{3} \mathrm{OD}$ ]. Chemical shifts are referred to the solvent signal and are expressed in ppm. 2D NMR experiments (COSY, TOCSY, ROESY, and HMQC) were carried out when necessary to assign the corresponding signals of the new compounds. High resolution FAB (+) mass spectral analyses was obtained on a Micromass AutoSpec-Q spectrometer.

\section{Preparation and characterization of maltose derivatives 17-20.}

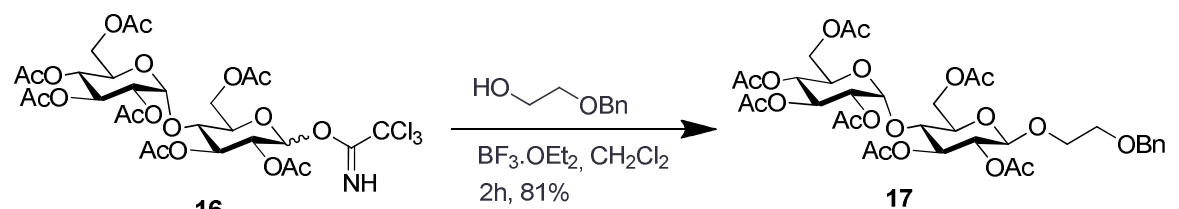

16

$2 \mathrm{~h}, 81 \%$
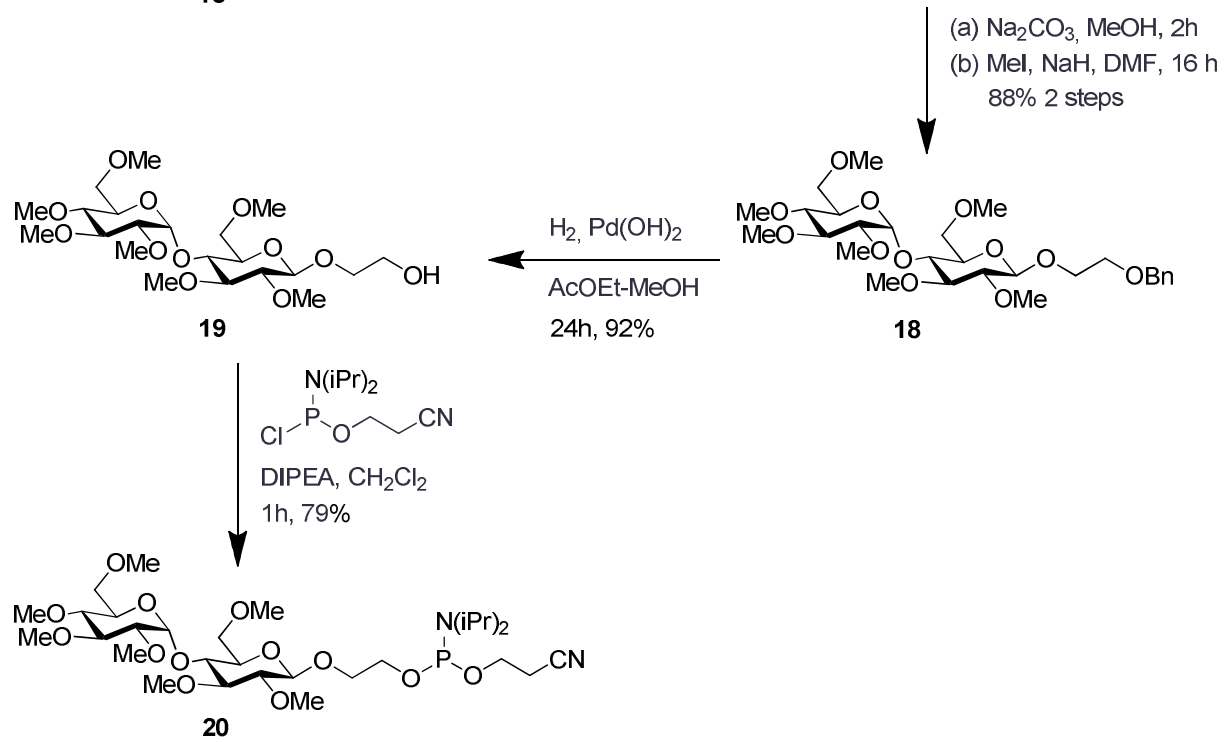

20 


\section{2-Benzyloxyethyl 2,3,6-tri- $O$-acetyl-4-O-(2,3,4,6-tetra- $O$-acetyl- $\alpha$-D-}

glucopyranosyl)- $\beta$-D-glucopyranoside (17)

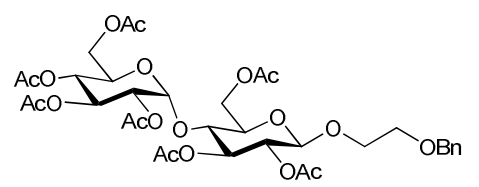

To a solution of the heptaacetyl maltose trichloroacetimidate $\mathbf{1 6}^{[1]}(4.5 \mathrm{~g}, 5.76 \mathrm{mmol})$ in anhydrous $\mathrm{CH}_{2} \mathrm{Cl}_{2}(50 \mathrm{~mL})$ and 2-benzyloxyethanol (1.6 mL, $\left.11.5 \mathrm{mmol}\right), \mathrm{BF}_{3} . \mathrm{OEt}_{2}(73$ $\mu \mathrm{l}, 0.57 \mathrm{mmol}$ ) was then added. After stirring at room temperature for $2 \mathrm{~h}$ under argon atmosphere, $\mathrm{NEt}_{3}(0.2 \mathrm{ml})$ was then added. Solvents were then removed and the crude was purified by silica gel column chromathography using as eluent (Hex-AcOEt, 2:12:3) to give $17(3.6 \mathrm{~g}, 81 \%)$ as a syrup. $[\alpha]_{\mathrm{D}}{ }^{22}+40.4\left(\mathrm{c} 1\right.$ in $\left.\mathrm{CHCl}_{3}\right) ; \delta_{\mathrm{H}}(300 \mathrm{MHz}$, $\left.\mathrm{CDCl}_{3}\right): 7.028-7.00(\mathrm{~m}, 5 \mathrm{H}, \mathrm{Ph}), 5.11\left(\mathrm{~d}, 1 \mathrm{H}, J=3.96 \mathrm{~Hz}, \mathrm{H}_{1 \mathrm{~B}}\right), 5.07(\mathrm{t}, 1 \mathrm{H}, J=10.0 \mathrm{~Hz}$, $\left.\mathrm{H}_{3 \mathrm{~B}}\right), 4.96\left(\mathrm{t}, 1 \mathrm{H}, J=9.0 \mathrm{~Hz}, \mathrm{H}_{3 \mathrm{~A}}\right), 4.75\left(\mathrm{t}, 1 \mathrm{H}, J=9.6 \mathrm{~Hz}, \mathrm{H}_{4 \mathrm{~B}}\right), 4.58-4.52\left(\mathrm{~m}, 2 \mathrm{H}, \mathrm{H}_{2 \mathrm{~A}}\right.$, $\left.\mathrm{H}_{2 \mathrm{~B}}\right), 4.35\left(\mathrm{~d}, 1 \mathrm{H}, J=7.8 \mathrm{~Hz}, \mathrm{H}_{1 \mathrm{~A}}\right), 4.23-4.15\left(\mathrm{~m}, 2 \mathrm{H}, \mathrm{CH}_{2}, \mathrm{H}_{6 \mathrm{~A}}\right), 3.99-3.90(\mathrm{~m}, 2 \mathrm{H}$, $\left.\mathrm{H}_{6 \mathrm{~B}}, \mathrm{H}_{6}{ }^{\prime} \mathrm{A}\right), 3.76-3.63$ (m, 4H, $\left.\mathrm{OCH}_{2}, \mathrm{H}_{5 \mathrm{~B}}, \mathrm{H}_{6}{ }^{\prime} \mathrm{B}\right), 3.49-3.34\left(\mathrm{~m}, 4 \mathrm{H}, \mathrm{H}_{5 \mathrm{~A}}, \mathrm{H}_{4 \mathrm{~A}}, \mathrm{OCH}_{2}\right)$, 1.90-1.66 (6s, 21H. $\left.\mathrm{OCOCH}_{3}\right) . \quad \delta_{\mathrm{C}}\left(75 \mathrm{MHz}, \mathrm{CDCl}_{3}\right): 170.5,170.4,170.3,170.1$, 169.8, 169.6, 169.3 (C=O), 138.1 (Cqarom), 128.3, 127.6, 127.5 (Carom), $100.3\left(\mathrm{C}_{1 \mathrm{~A}}\right)$, $95.5\left(\mathrm{C}_{1 \mathrm{~B}}\right), 75.3,73.1,72.7,72.1,72.0,69.9,69.2,69.0,68.4,67.7,62.8,61.4,20.9$, 20.8, 20.7, 20.6, 20.5. HRMS $\left(\mathrm{ES}^{+}\right)$Calcd. for $\mathrm{C}_{35} \mathrm{H}_{46} \mathrm{O}_{19} \mathrm{Na}(\mathrm{M}+\mathrm{Na})$ : 793.2531, found; 793.2549 .

\section{2-Benzyloxyethyl 2,3,6-tri- $O$-methyl-4-O-(2,3,4,6-tetra- $O$-methyl- $\alpha$-D-} glucopyranosyl)- $\beta$-D-glucopyranoside (18)

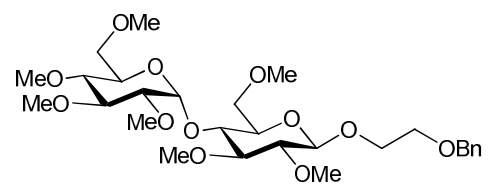

Compound $17(3.0 \mathrm{~g}, 3.89 \mathrm{mmol})$ was dissolved in dry $\mathrm{MeOH}(100 \mathrm{~mL})$ and $\mathrm{Na}_{2} \mathrm{CO}_{3}$ (162 $\mathrm{mg}, 1.17 \mathrm{mmol}$ ) was then added. The reaction mixture was stirred for $2 \mathrm{~h}$ and IR120 was then added to neutralize. Solvent was then removed and the crude was used for next step without any further purification. To a solution of the crude $(2.0 \mathrm{~g}, 4.2 \mathrm{mmol})$ in anhydrous DMF $(200 \mathrm{~mL})$ at $0^{\circ} \mathrm{C}, \mathrm{NaH}(1.4 \mathrm{~g}, 58.8 \mathrm{mmol})$ was added. The reaction 
mixture was stirred for $10 \mathrm{~min}$ and $\mathrm{MeI}(5.5 \mathrm{~mL}, 88.2 \mathrm{mmol})$. After $24 \mathrm{~h} \mathrm{2}$-propanol was then added dropwise and $\mathrm{NH}_{4} \mathrm{Cl}$ sat $(50 \mathrm{~mL})$. Organic phase was extracted with ethyl acetate $(2 \times 200 \mathrm{~mL})$ and washed with sodium bisulfate solution $(100 \mathrm{~mL})$ and brine $(100 \mathrm{~mL})$. Solvents were then removed and the crude was purified by silica gel column chromathography using as eluent (Hex-AcOEt, 1:1-1:6) to give 18 (1.9 g, 88\%) as a syrup. $[\alpha]_{\mathrm{D}}{ }^{20}+38.9\left(\mathrm{c} 1\right.$ in $\left.\mathrm{CHCl}_{3}\right) ; \delta_{\mathrm{H}}\left(300 \mathrm{MHz}, \mathrm{CDCl}_{3}\right): 7.08-7.01(\mathrm{~m}, 5 \mathrm{H}, \mathrm{Ph})$, $5.39\left(\mathrm{~d}, 1 \mathrm{H}, J=3.90 \mathrm{~Hz}, \mathrm{H}_{1 \mathrm{~B}}\right), 4.308\left(\mathrm{~s}, 2 \mathrm{H}, \mathrm{CH}_{2} \mathrm{Ph}\right), 4.06\left(\mathrm{~d}, 1 \mathrm{H}, J=7.8 \mathrm{~Hz}, \mathrm{H}_{1 \mathrm{~A}}\right)$, $3.77\left(\mathrm{~m}, 1 \mathrm{H}, \mathrm{H}_{6 \mathrm{~A}}\right), 3.57$ (t, $\left.1 \mathrm{H}, J=9.0 \mathrm{~Hz}, \mathrm{H}_{3 \mathrm{~B}}\right), 3.51-3.24\left(\mathrm{~m}, 23 \mathrm{H}, \mathrm{H}_{6}{ }^{\prime} \mathrm{A}, 2 \mathrm{xCH}_{2}, \mathrm{H}_{5 \mathrm{~A}}\right.$ $\left.\mathrm{H}_{5 \mathrm{~B}}, \mathrm{H}_{6 \mathrm{~B}}, 5 \mathrm{xCH}_{3} \mathrm{O}\right), 3.19-3.14\left(\mathrm{~m}, 6 \mathrm{H}, \mathrm{H}_{3 \mathrm{~A}}, \mathrm{H}_{4 \mathrm{~B}}, \mathrm{H}_{6}{ }^{\prime} \mathrm{B}, \mathrm{CH}_{3} \mathrm{O}\right), 3.06$ (s, 3H, $\left.\mathrm{CH}_{3} \mathrm{O}\right), 3.00$ $\left(\mathrm{t}, 1 \mathrm{H}, J=9.0 \mathrm{~Hz}, \mathrm{H}_{3 \mathrm{~B}}\right), 2.93\left(\mathrm{dd}, 1 \mathrm{H}, J=3.6,10.0 \mathrm{~Hz}, \mathrm{H}_{2 \mathrm{~B}}\right), 2.4(\mathrm{t}, 1 \mathrm{H}, J=8.7 \mathrm{~Hz}$, $\left.\mathrm{H}_{2 \mathrm{~A}}\right) . \delta^{13}{ }_{\mathrm{C}}\left(100 \mathrm{MHz}, \mathrm{CDCl}_{3}\right)$ : 138.2 (Cqarom), 128.3, 127.6, 127.5 (Carom), 103.4 $\left(\mathrm{C}_{1 \mathrm{~A}}\right), 95.9\left(\mathrm{C}_{1 \mathrm{~B}}\right), 86.3,83.7,83.3,81.7,79.1,73.6,70.1,71.0,70.6,69.2,68.8,60.7$, 60.4, 60.1, 59.4, 59.3, 59.2, 59.1. HRMS $\left(\mathrm{ES}^{+}\right)$Calcd. for $\mathrm{C}_{21} \mathrm{H}_{40} \mathrm{O}_{12} \mathrm{Na}(\mathrm{M}+\mathrm{Na})$ : 507.2417, found; 507.2433.

\section{2-Hydroxyethyl 2,3,6-tri- $O$-methyl-4-O-(2,3,4,6-tetra- $O$-methyl- $\alpha$-D-} glucopyranosyl)- $\beta$-D-glucopyranoside (19)

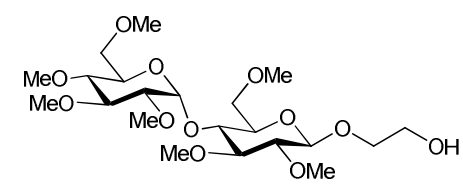

A solution of compound $18(500 \mathrm{mg}, 0.87 \mathrm{mmol})$ in ethyl acetate-MeOH $(1: 1,5 \mathrm{~mL})$ and $\mathrm{Pd}(\mathrm{OH})_{2}$ in catalytic amount was stirred under an atmosphere of hydrogen for $24 \mathrm{~h}$. The mixture was filtered off over celite and solvents were removed. The crude was purified by silica gel column chromathography using as eluent (Hex-AcOEt, 1:6 $\rightarrow 0: 1$ ) to give $19(386 \mathrm{mg}, 92 \%)$ as a syrup. $[\alpha]_{\mathrm{D}}{ }^{20}+74.0$ (c 1 in $\left.\mathrm{CHCl}_{3}\right) ; \delta_{\mathrm{H}}(500 \mathrm{MHz}$, $\left.\mathrm{CDCl}_{3}\right): 5.39\left(\mathrm{~s}, 1 \mathrm{H}, 4.06\left(\mathrm{~d}, 1 \mathrm{H}, J=7.5 \mathrm{~Hz}, \mathrm{H}_{1 \mathrm{~A}}\right), 3.90\left(\mathrm{~m}, 1 \mathrm{H}, \mathrm{H}_{6 \mathrm{~A}}\right), 3.81(\mathrm{~m}, 1 \mathrm{H}\right.$, $\mathrm{H}_{3 \mathrm{~B}}$ ), 3.74-3.37 (m, 33H, $\left.\mathrm{H}_{6}{ }^{\prime} \mathrm{A}, 2 \mathrm{xCH}_{2}, \mathrm{H}_{5 \mathrm{~A}} \mathrm{H}_{5 \mathrm{~B}}, \mathrm{H}_{6 \mathrm{~B}}, 6 \mathrm{CH}_{3} \mathrm{O}, \mathrm{H}_{3 \mathrm{~A}}, \mathrm{H}_{4 \mathrm{~B}}, \mathrm{H}_{6}{ }^{\prime} \mathrm{B}\right), 3.30$ (s, $\left.3 \mathrm{H}, \mathrm{CH}_{3} \mathrm{O}\right), 3.2\left(\mathrm{t}, 1 \mathrm{H}, J=9.0 \mathrm{~Hz}, \mathrm{H}_{3 \mathrm{~B}}\right), 3.18-3.14\left(\mathrm{~m}, 1 \mathrm{H}, \mathrm{H}_{2 \mathrm{~B}}\right), 3.06(\mathrm{t}, 1 \mathrm{H}, J=8.0 \mathrm{~Hz}$, $\left.\mathrm{H}_{2 \mathrm{~A}}\right) . \delta^{13}{ }_{\mathrm{C}}\left(125 \mathrm{MHz}, \mathrm{CDCl}_{3}\right): 103.9\left(\mathrm{C}_{1 \mathrm{~A}}\right), 96.3\left(\mathrm{C}_{1 \mathrm{~B}}\right), 86.3,83.9,83.3,81.7,79.2,73.5$, 
73.4, 72.0, 71.4, 70.8, 70.7, 62.4, 60.7, 60.5, 60.3, 59.7, 59.5, 59.2, 59.0. HRMS $\left(\mathrm{ES}^{+}\right)$

Calcd. for $\mathrm{C}_{21} \mathrm{H}_{40} \mathrm{O}_{12} \mathrm{Na}(\mathrm{M}+\mathrm{Na})$ : 507.2417, found; 507.2433.

\section{2-[(2,3,4,6-Tetra- $O$-methyl- $\alpha$-D-glucopyranosyl-(1 $\rightarrow 4)-2,3,6$-tri- $O$-methyl- $\beta$-D-} glucopyranosyloxy)]ethyl (2-cyanoethyl) ( $N, N$-diisopropyl) phosphoramidite (20)

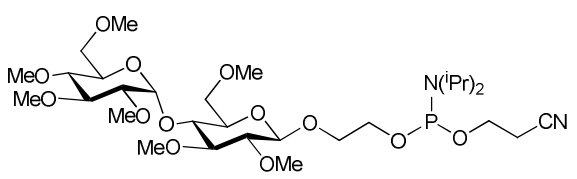

DIEA $(260 \mu \mathrm{L}, \quad 1.48 \quad \mathrm{mmol})$ and 2-cyanoethyl- $N, N^{\prime}$-diisopropylaminochlorophosphoramidite ( $125 \mu \mathrm{L}, 0.55 \mathrm{mmoL}$ ) were added to a solution of compound 19 (180 mg, $0.37 \mathrm{mmol})$ in anhydrous $\mathrm{CH}_{2} \mathrm{Cl}_{2}(4 \mathrm{~mL})$ at room temperature under an argon atmosphere. After $1.0 \mathrm{~h}$ no starting material was observed. Solvent was then removed and the crude was purified by silica gel column chromatography by using Hex/EtOAc (1:2 with $5 \%$ of $\left.\mathrm{NEt}_{3}\right)$ to give compound $20(200 \mathrm{mg}, 79 \%)$ as a syrup. $\delta_{\mathrm{H}}^{1}(300 \mathrm{MHz}$, $\left.\mathrm{CDCl}_{3}\right): 5.41\left(\mathrm{~d}, 1 \mathrm{H}, J=3.90 \mathrm{~Hz}, \mathrm{H}_{1 \mathrm{~B}}\right), 4.04\left(\mathrm{~d}, 1 \mathrm{H}, J=7.8 \mathrm{~Hz}, \mathrm{H}_{1 \mathrm{~A}}\right), 3.79-3.74(\mathrm{~m}$, $\left.1 \mathrm{H}, \mathrm{H}_{6 \mathrm{~A}}\right), 3.65-3.45\left(\mathrm{~m}, 6 \mathrm{H}, \mathrm{H}_{3 \mathrm{~B}}, \mathrm{H}_{6}{ }^{\prime} \mathrm{A}, 2 \mathrm{xCH}_{2}\right), 3.44-3.27\left(\mathrm{~m}, 22 \mathrm{H}, \mathrm{OCH}_{2}, 2 \mathrm{xCH}_{\text {isopropyl }}\right.$ , $\left.\mathrm{H}_{5 \mathrm{~A}} \mathrm{H}_{5 \mathrm{~B}}, \mathrm{H}_{6 \mathrm{~B}}, 5 \mathrm{xCH}_{3} \mathrm{O}\right), 3.21-3.10\left(\mathrm{~m}, 6 \mathrm{H}, \mathrm{H}_{3 \mathrm{~A}}, \mathrm{H}_{4 \mathrm{~B}}, \mathrm{H}_{6}{ }^{\prime}, \mathrm{CH}_{3} \mathrm{O}\right), 3.06(\mathrm{~s}, 3 \mathrm{H}$, $\left.\mathrm{CH}_{3} \mathrm{O}\right), 3.02\left(\mathrm{t}, 1 \mathrm{H}, J=9.0 \mathrm{~Hz}, \mathrm{H}_{3 \mathrm{~B}}\right), 2.96\left(\mathrm{dd}, 1 \mathrm{H}, J=3.6,10.0 \mathrm{~Hz}, \mathrm{H}_{2 \mathrm{~B}}\right), 2.87-2.80(\mathrm{~m}$, $\left.1 \mathrm{H}, \mathrm{H}_{2 \mathrm{~A}}\right), 2.22-2.39\left(\mathrm{~m}, 2 \mathrm{H}, \underline{\mathrm{H}}_{2} \mathrm{CN}\right), 0.98\left(\mathrm{~d}, 12 \mathrm{H}, J=6.5 \mathrm{~Hz}, 4 \mathrm{CH}_{3 \text { isopropyl }}\right) . \delta^{13}{ }_{\mathrm{C}}$ $\left(100 \mathrm{MHz}, \mathrm{CDCl}_{3}\right)$ : $117.9(\mathrm{CN}), 103.5\left(\mathrm{C}_{1 \mathrm{~A}}\right), 95.9\left(\mathrm{C}_{1 \mathrm{~B}}\right)$, 86.3, 83.7, 83.3, 81.7, 79.1, 73.6, 71.0, 70.6, 69.3, 62.5, 60.8, 60.5, 60.2, 59.4, 59.3, 59.2, 59.1, 58.4, 43.0, 24.7, 24.6, 24.5, 20.3. HRMS $\left(\mathrm{ES}^{+}\right)$Calcd. for $\mathrm{C}_{28} \mathrm{H}_{46} \mathrm{O}_{12} \mathrm{Na}(\mathrm{M}+\mathrm{Na})$ : 597.2887, found; 597.2882 . 
Proton and carbon NMR spectra of compounds 17-20.
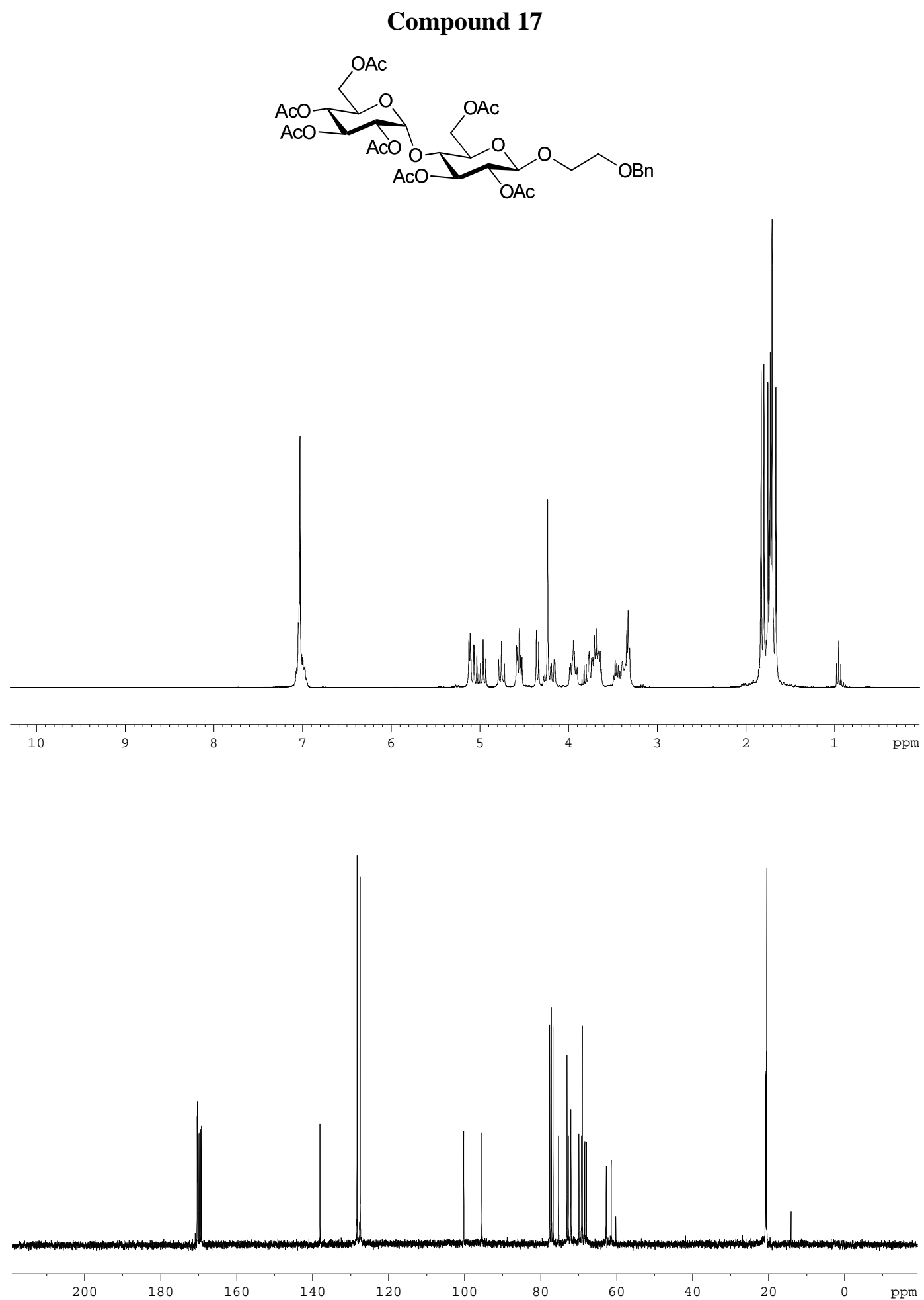

Compound 18 

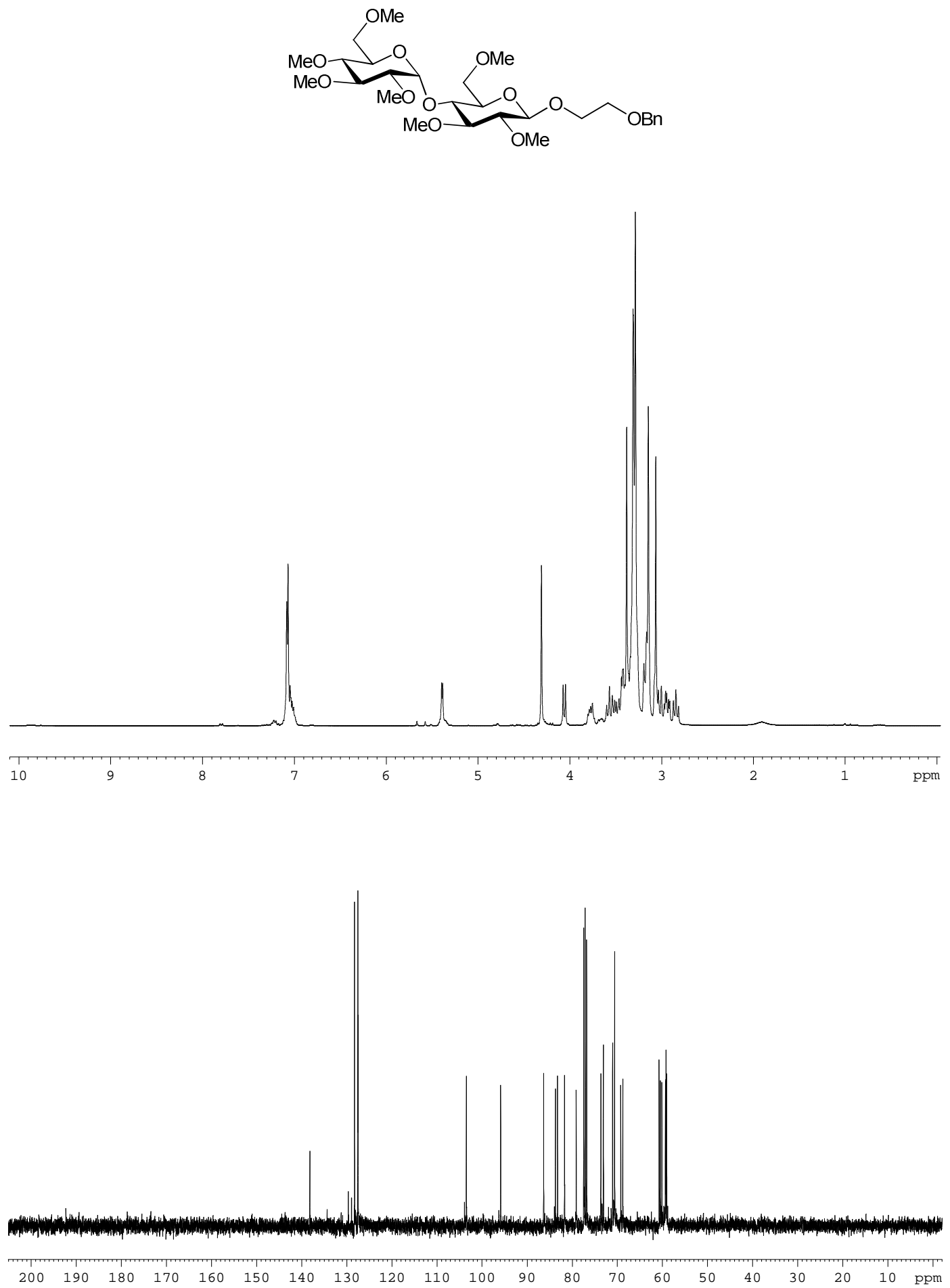

\section{Compound 19}

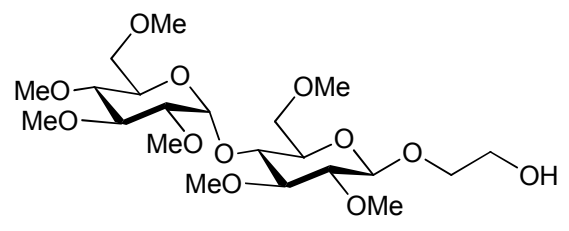




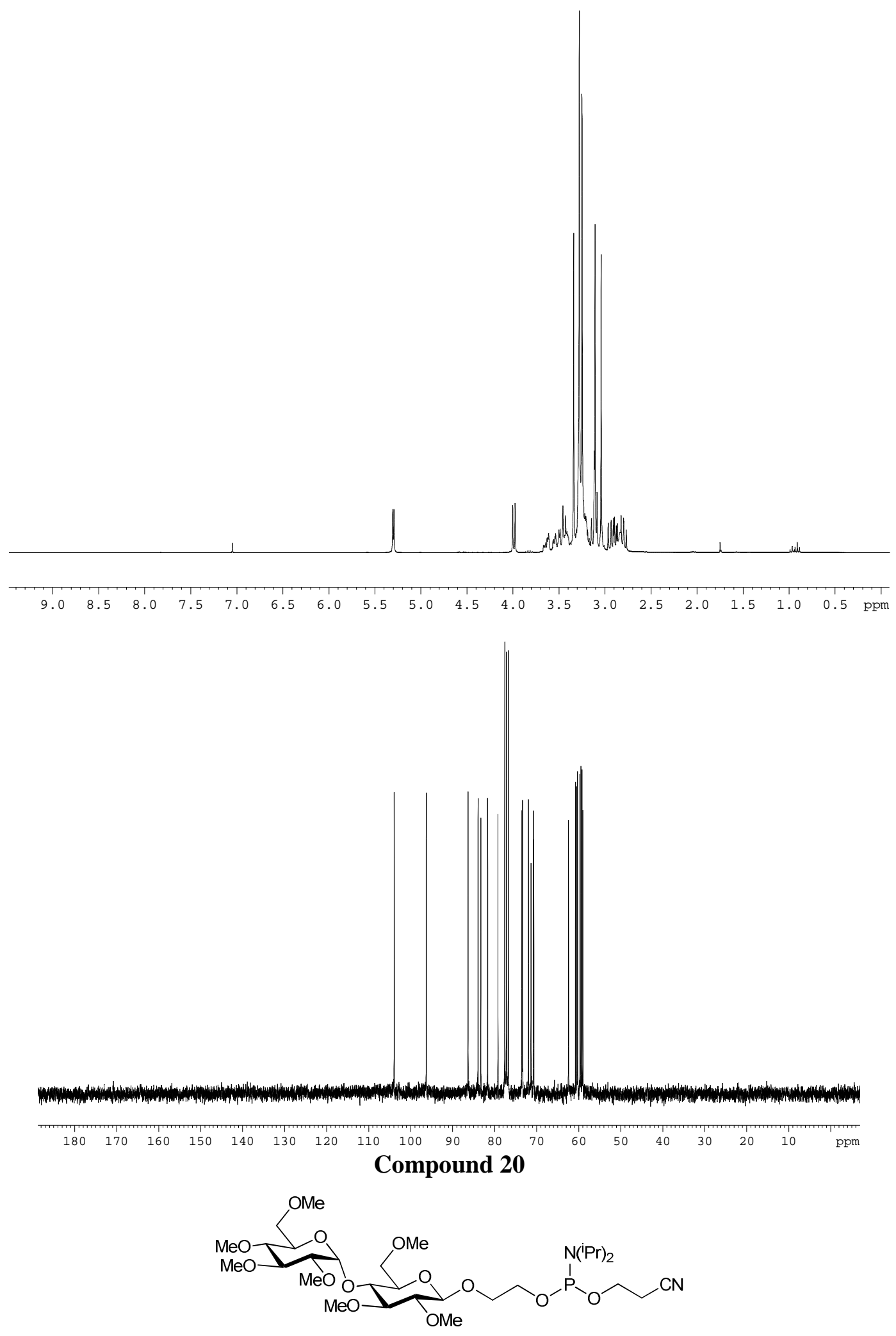



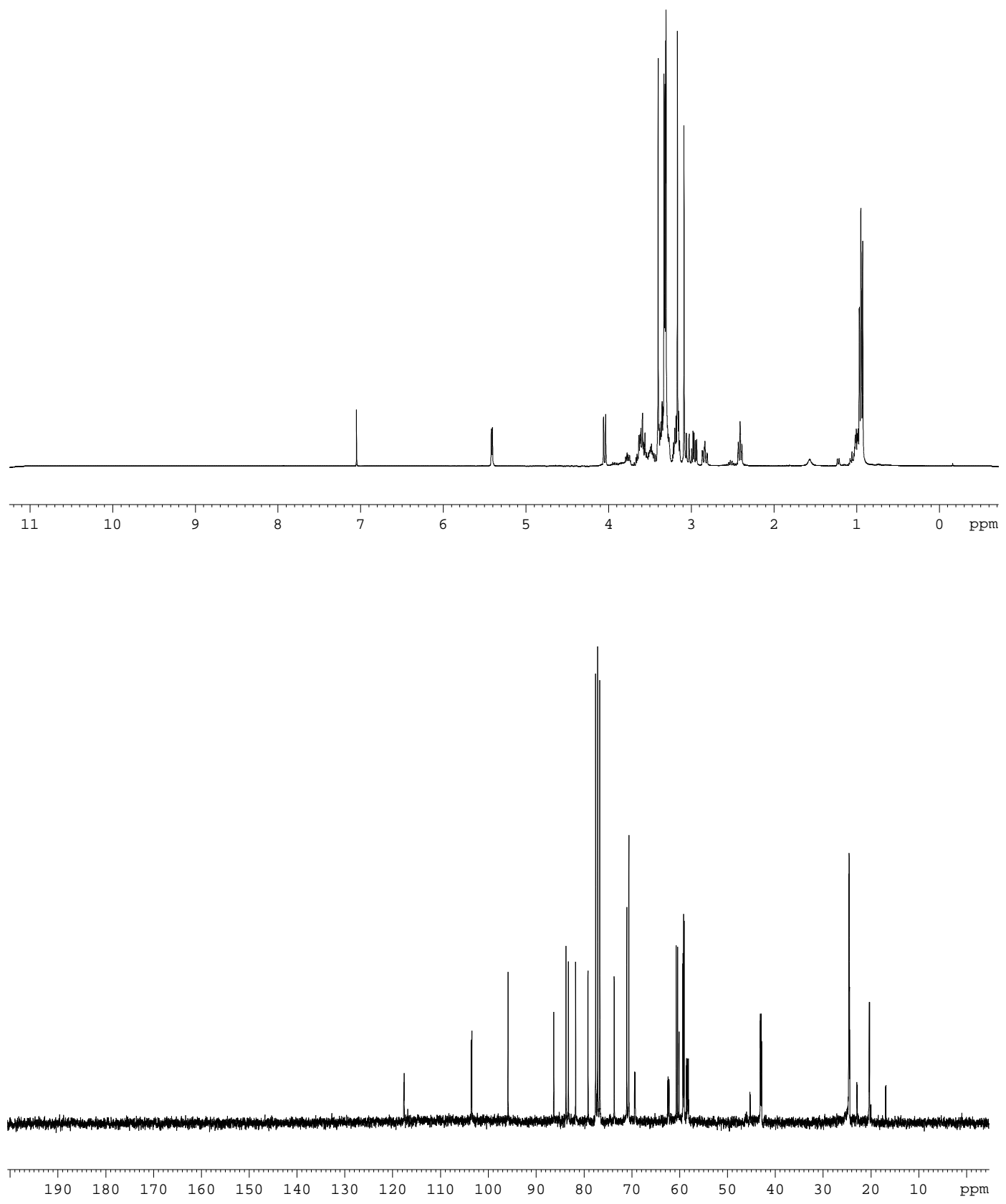


\section{Synthesis of carbohydrate-oligonucleotide conjugates}

Carbohydrate-oligonucleotide conjugates 4-11 were synthesized on an Applied Biosystems 3400 synthesizer by using standard $\beta$-cyanoethylphosphoramidite chemistry. G-quadruplex oligonucleotide sequences 1-3, 12, 13, 14 and 15 were prepared by Biomers following the same methodology. Oligonucleotide conjugates were synthesized either on low-volume 200 nmols (LV200) or $1.0 \mu \mathrm{mol}$ scale and using the DMT-off procedure. Oligonucleotide supports were treated with $33 \%$ aqueous ammonia for $16 \mathrm{~h}$ at $55^{\circ} \mathrm{C}$, then the ammonia solutions were evaporated to dryness and the conjugates were purified by reversed-phase HPLC in a Waters Alliance separation module with a PDA detector. HPLC conditions were as follows: Nucleosil $120 \mathrm{C} 18$, 250x8 mm, $10 \mu \mathrm{m}$ column; flow rate: $3 \mathrm{~mL} / \mathrm{min}$.

For conjugates 4-9: A 28 min linear gradient 0-30\%B (mobile phase A: $5 \% \mathrm{CH}_{3} \mathrm{CN}$ / 95\% $100 \mathrm{mM}$ triethylammonium acetate (TEAA; pH 6.5); mobile phase B: $100 \%$ $\left.\mathrm{CH}_{3} \mathrm{CN}\right)$.

For conjugates 10-11: A 28 min linear gradient 0-40\%B (mobile phase $\mathrm{A}$ : $5 \% \mathrm{CH}_{3} \mathrm{CN}$ / 95\% $100 \mathrm{mM}$ triethylammonium acetate (TEAA; pH 6.5); mobile phase B: $100 \%$ $\left.\mathrm{CH}_{3} \mathrm{CN}\right)$.

\section{Thermal denaturation UV measurements}

TBA control oligonucleotides 1-3, carbohydrate-TBA conjugates 4-11 and TBA derivatives 12-13 were hybridized by heating the sample at $90^{\circ} \mathrm{C}$ for $3 \mathrm{~min}$ and letting cool down to room temperature during $3 \mathrm{~h}$. Melting curves for the DNA conjugates were measured in a Perkin-Elmer Lambda $750 \mathrm{UV} /$ Vis spectrophotometer at $295 \mathrm{~nm}$ while the temperature was raised from 10 to $80{ }^{\circ} \mathrm{C}$ at a rate of $1.0^{\circ} \mathrm{C} / \mathrm{min}$. Tm values were calculated from the first derivative of the melting curve (using Origin software). ${ }^{[2]}$ 
HPLC chromatograms of carbohydrate oligonucleotide conjugates 4-11 and 14.

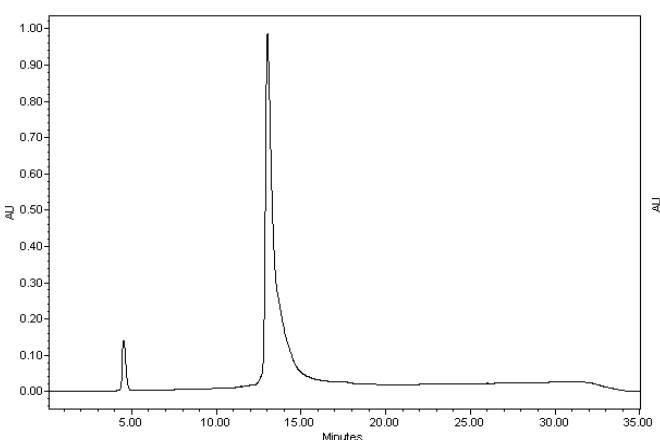

Conjugate $\beta$-D-glc-C2-TBA seq (4)

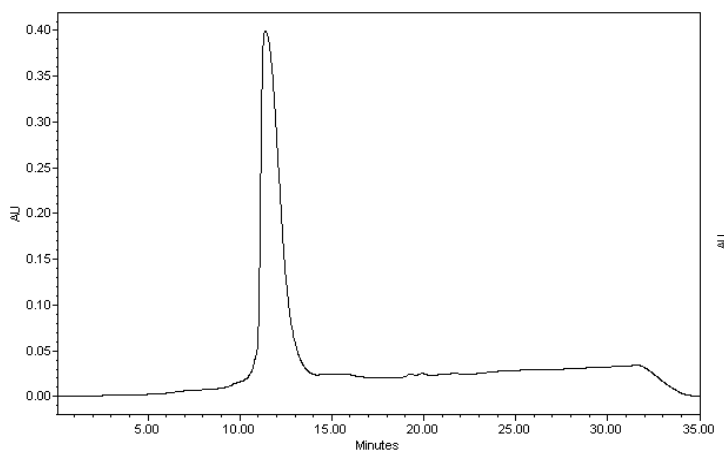

Conjugate $\beta$-L-Fuc-C2-TBA seq (6)

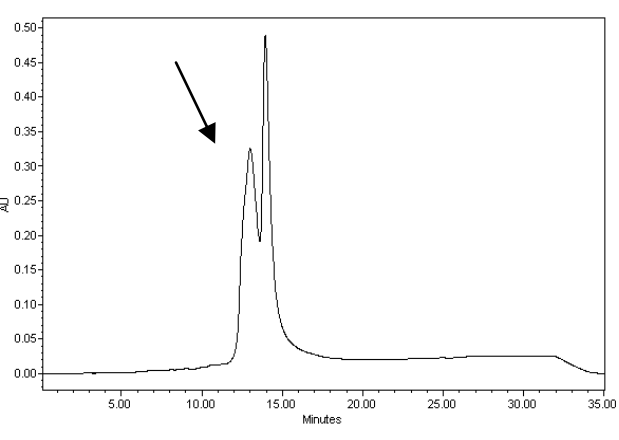

Conjugate $\beta$-D-gal-C2-TBA seq (5)

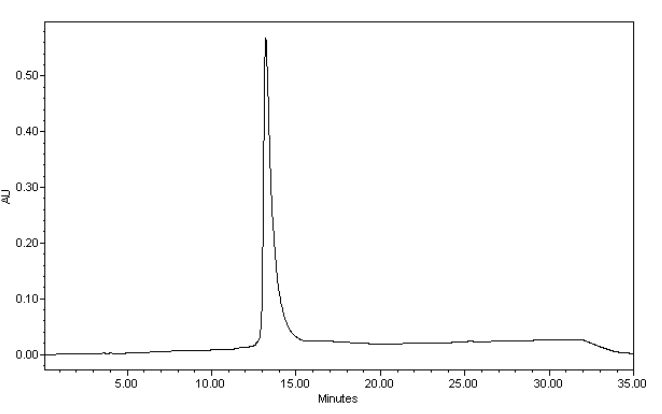

Conjugate $\beta$-D-maltose-C2-TBA seq

(7)

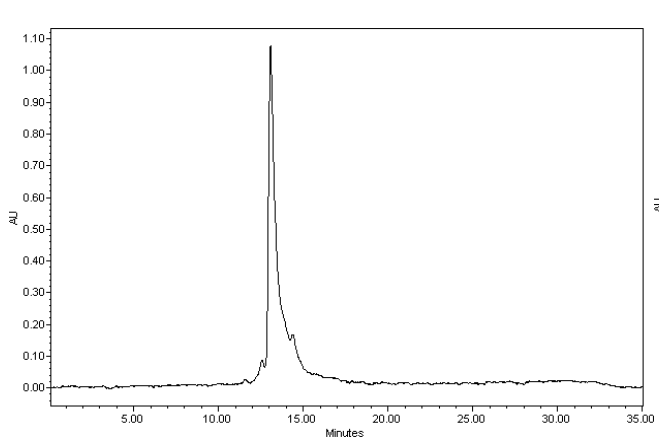

Conjugate $\beta$-D-lactose-C2-TBA seq (8) seq (9)

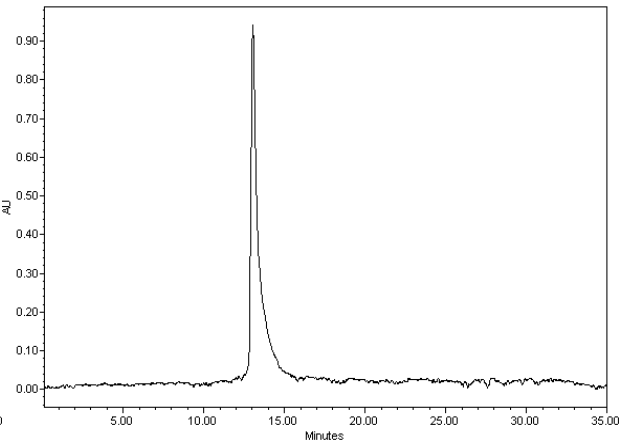

Conjugate $\quad \beta$-D-cellobiose-C2-TBA 


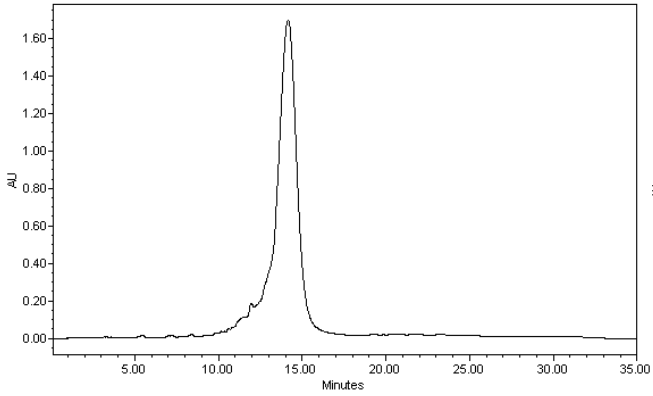

Conjugate $\beta$-D-glc(Me)-C2-TBA seq (10) seq (11)

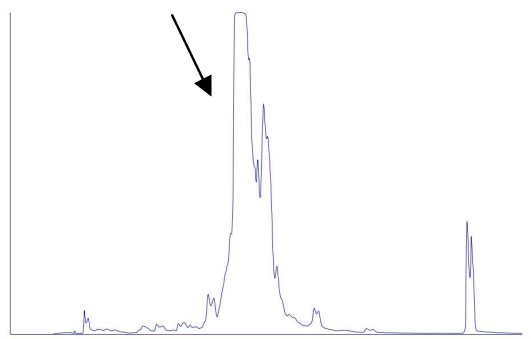

Conjugate $\beta$-D-glc(Me)-C2- $\mathrm{OPO}_{2}^{-}$-AGGGTTAGGGT (14)

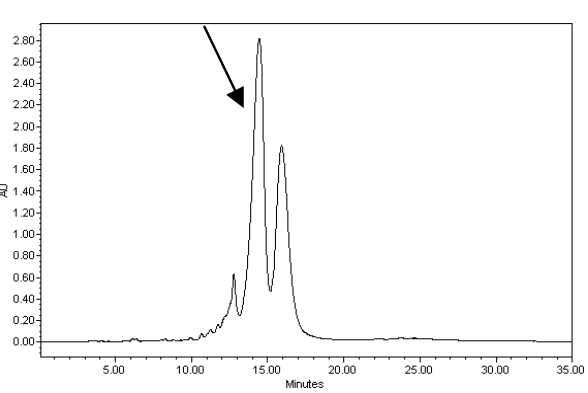

Conjugate $\beta$-D-maltose(Me)-C2-TBA 
Maldi-TOF mass spectra of carbohydrate oligonucleotide conjugates 4-11 and 14.

MALDI-TOF spectra were performed using a Perseptive Voyager DETMRP mass spectrometer, equipped with nitrogen laser at $337 \mathrm{~nm}$ using a $3 \mathrm{~ns}$ pulse. The matrix used contained 2,4,6-trihydroxyacetophenone (THAP, $10 \mathrm{mg} / \mathrm{ml}$ in ACN/ water 1:1) and ammonium citrate $(50 \mathrm{mg} / \mathrm{ml}$ in water $)$.

\section{Carbohydrate oligonucleotide conjugates $\quad[\mathrm{M}-\mathrm{H}]$ calc. $\quad[\mathrm{M}-\mathrm{H}]$ exp.}

\begin{tabular}{rlc}
\hline$\beta$-D-glc-C2-GGTTGGTGTGGTTGG (4) & 5003.1 & 5003.4 \\
$\beta$-D-gal-C2-GGTTGGTGTGGTTGG (5) & 5003.1 & 5003.0 \\
$\beta$-L-Fuc-C2-GGTTGGTGTGGTTGG (6) & 4987.1 & 4987.7 \\
$\beta$-D-maltose-C2-GGTTGGTGTGGTTGG (7) & 5165.1 & 5164.8 \\
$\beta$-D-lactose-C2-GGTTGGTGTGGTTGG (8) & 5165.1 & 5164.4 \\
$\beta$-D-cellobiose-C2-GGTTGGTGTGGTTGG (9) & 5165.1 & 5166.6 \\
$\beta$-D-glc(Me)-C2-GGTTGGTGTGGTTGG (10) & 5263.5 & 5263.1 \\
$\beta$-D-maltose(Me)-C2-GGTTGGTGTGGTTGG (11) & 5059.3 & 5059.0 \\
$\beta$-D-glc-C2-AGGGTTAGGGT (14) & 3740.0 & 3739.0
\end{tabular}




\section{NMR spectroscopy and structure calculations.}

Samples of the conjugates were purified by HPLC, ion-exchanged with Dowex 50W resin and then suspended in $500 \mu \mathrm{L}$ of either $\mathrm{D}_{2} \mathrm{O}$ or $\mathrm{H}_{2} \mathrm{O} / \mathrm{D}_{2} \mathrm{O}$ 9:1 in potassium phosphate buffer, $\mathrm{pH}$ 7. Different $\mathrm{KCl}$ concentrations were used for NMR samples, ranging from 5 to $100 \mathrm{mM}$. NMR spectra were acquired in Bruker Avance spectrometers operating at 600 or $800 \mathrm{MHz}$, and processed with Topspin software. DQF-COSY, TOCSY and NOESY (mixing times of 150 and 300ms) experiments were recorded in $\mathrm{D}_{2} \mathrm{O}$ at temperatures ranging from $5{ }^{\circ} \mathrm{C}$ to $25^{\circ} \mathrm{C}$. NOESY spectra in $\mathrm{H}_{2} \mathrm{O}$ were acquired with $100 \mathrm{~ms}$ mixing time at $5{ }^{\circ} \mathrm{C}$ to reduce the exchange with water. The spectral analysis program Sparky ${ }^{[3]}$ was used for semiautomatic assignment of the NOESY cross-peaks and quantitative evaluation of the NOE intensities.

142 distance constraints with their corresponding error bounds were incorporated into the $\mathrm{AMBER}^{[4]}$ potential energy by defining a flat-well potential term. Additional restraints to preserved G-tetrad planarity were included. Restrained molecular dynamics calculations were carried out following protocols described in our previous study. ${ }^{[5]}$

Initial model structures of carbohydrate-TBA conjugates were built from unmodified TBA structure (PDB: 148D) by connecting the carbohydrate and glycerol and phosphate linker with the program Sybyl. The initial structures were refined including explicit solvent, periodic boundary conditions and the Particle-Mesh-Ewald method to evaluate long-range electrostatic interactions. Force field parameters for the carbohydrate moieties were taken from GLYCAM, ${ }^{[6]}$ and the TIP3P model was used to describe water molecules. $^{[7]}$ Analysis of the representative structures as well as the MD trajectories was carried out with the program MOLMOL ${ }^{[8]}$ and the analysis tools of AMBER.

Ten final structures of conjugate 6 obtained from an explicit solvent refinement are displayed in Figure 5A in the main text. The calculations converge to a well-defined structure, with an RMSD for all heavy atoms of $0.4 \AA$. The final AMBER energies and NOE terms are reasonably low in all the structures, which do not exhibit significant constraint violations. 


\section{References}

[1] R. R. Schmidt, J. Michel, Angew. Chem. Int. Ed. 1980, 19, 731-732.

[2] a) S. G. Lokhov, D. V. Pyshnyi, FEBS Lett 1997, 420, 134-138; b) T. Ohmichi, S. Nakano, D. Miyoshi, N. Sugimoto, J Am Chem Soc 2002, 124, 10367-10372.

[3] D. T. Goddard, G. Kneller, 3. ed., University of California, San Francisco.

[4] D. A. Case, D. A. Pearlman, J. W. Caldwell, T. E. C. III, W. S. Ross, C. L. Simmerling, T. A. Darden, K. M. Merz, R. V. Stanton, A. L. Cheng, J. J. Vincent, M. Crowley, D. M. Ferguson, R. J. Radmer, G. L. Seibel, U. C. Singh, P. K. Weiner, P. A. Kollman, 5 ed., University of California, San Francisco, 1997.

[5] a) R. Lucas, I. Gómez-Pinto, A. Aviñó, J. J. Reina, R. Eritja, C. González, J. C. Morales, J Am Chem Soc 2011, 133, 1909-1916; b) R. Soliva, V. Monaco, I. Gomez-Pinto, N. J. Meeuwenoord, G. A. Marel, J. H. Boom, C. Gonzalez, M. Orozco, Nucleic Acids Res 2001, 29, 2973-2985.

[6] R. J. Woods, R. A. Dwek, C. J. Edge, D. Fraser-Reid, J. Phys. Chem. 1995, 99, 3832-3839.

[7] W. L. Jorgensen, J. Chandrasekhar, J. D. Madura, R. W. Impey, M. L. Klein, J. Chem. Phys. 1983, 79, 926-935.

[8] R. Koradi, M. Billeter, K. Wuthrich, J. Mol. Graphics 1996, 14, 29-32. 